\title{
Brains in the City: Neurobiological effects of urbanization
}

\author{
Kelly G. Lambert \\ Department of Psychology, Randolph-Macon College, Ashland VA 23005 \\ Randy J. Nelson \\ Department of Neuroscience, The Ohio State University Wexner Medical Center, \\ Columbus, OH 43210 USA. \\ Tanja Jovanovic \\ Department of Psychiatry \& Behavioral Sciences \\ Emory University School of Medicine, Atlanta, GA 30303 \\ Magdalena Cerdá
}

Department of Epidemiology, Columbia University, New York, NY 10032

Corresponding Author:

Kelly G. Lambert, Department of Psychology, Copley Science Center Rm. 134B, Randolph-

Macon College, Ashland VA USA 23005; klambert@rmc.edu; 804-752-4717 


\begin{abstract}
:
With a majority of humans now living in cities, strategic research is necessary to elucidate the impact of this evolutionarily unfamiliar habitat on neural functions and well-being. In this review, both rodent and human models are considered in the evaluation of the changing physical and social landscapes associated with urban dwellings. Animal models assessing increased exposure to artificial physical elements characteristic of urban settings, as well as exposure to unnatural sources of light for extended durations, are reviewed. In both cases, increased biomarkers of mental illnesses such as major depression have been observed. Additionally, applied human research emphasizing the emotional impact of environmental threats associated with urban habitats is considered. Subjects evaluated in an inner-city hospital reveal the impact of combined specific genetic vulnerabilities and heightened stress responses in the expression of posttraumatic stress disorder. Finally, algorithm-based models of cities have been developed utilizing population-level analyses to identify risk factors for psychiatric illness. Although complex, the use of multiple research approaches, as described herein, results in an enhanced understanding of urbanization and its far-reaching effects--confirming the importance of continued research directed toward the identification of putative risk factors associated with psychiatric illness in urban settings.
\end{abstract}

\title{
Keywords:
}

Urbanization; Psychiatric illness; Natural environment; Light pollution; Depression; Socioeconomic Disadvantage; Intercity violence; PTSD; Self-efficacy; Collective Efficacy; Animal models; Agent-based models 


\section{Acknowledgements:}

KGL: This work was supported by the Macon and Joan Brock Neuroscience Professorship, Schapiro Summer Fellowships, Chenery Professorship and the Laughon Fund. A special thanks is extended to valued collaborators including Dr. Massimo Bardi and several former students, especially Molly Hyer and Casey Kaufman.

RJN: We thank Dr. Tracy Bedrosian for assistance with this paper. Support of RJN during the preparation of this review was by NSF grant IOS-11-18792.

TJ: We thank Drs. Kerry Ressler and Bakh Bradley, PIs of the Grady Trauma Project, as well as Allen Graham and Angelo Brown and the many GTP interns. We also thank Dr. Jennifer Stevens for her work in neuroimaging. This research was supported by National Institute of Mental Health Grants MH071537, MH096764 (PI, K.J.R.), MH098212, MH092576, and MH100122 (PI, T.J.), and the Howard Hughes Medical Institute (K.J.R.)

MC: We would like to thank Dr. Sandro Galea for providing critical input into our review of population-level approaches to understanding the influence of the urban environment on mental health, and Ms. Spruha Joshi for assisting in the review of the literature for this section. 


\section{Contents:}

\section{Introductory Comments}

2. The effects of natural and artificial habitats on environmental engagement and emotional resilience

2.1 The neural impact of qualitatively different environments

2.2 Urban and rural environmental influence

2.3 Environmental engagement, contingency building and emotional resilience

2.4 Conclusion

3. Effects of light pollution on neuroinflamation and mood

3.1 Light at night

3.2 Effects of light at night on humans

3.3 Effects of light at night on nonhuman animals

3.4 Conclusion

4. Violence in the city: Biomarkers in children and adults

4.1 Brain response to fear

4.2 Fear conditioning

4.3 Biomarkers of fear in children

4.4 Transgenerational effects

4.5 Conclusion

5. Translating animal research to humans: A population-level lens on the urban environment and brain disorders

5.1 Population-level patterns of brain disorders on urban vs. rural environments

5.2 How can the urban environment shape mood and anxiety disorders? 
5.3 The next step: Generating effective intervention strategies

5.4 Using complex systems approaches to identify promising intervention strategies in urban neighborhoods

6. Concluding Remarks 


\section{Brains in the City: Neurobiological effects of urbanization}

\section{Introductory comments}

Humans have the ability to exist in a broad range of environments, demonstrating that they can survive by hunting and fishing in the Arctic, foraging on the African savanna, or living in urban habitats (Laland and Brown, 2006). For the first time in human history, the majority of the world's population lives in urban areas. One hundred years ago, $20 \%$ of people lived in urban areas; by 2010 , more than $50 \%$ of the global population lived in a city. By 2030 , it is estimated that $70 \%$ of people will live in urban areas (World Health, 2012). In the United States and Canada, for example, $80 \%$ of the population lives in urban dwellings (UN-DESA, 2011; Schewenius et al., 2014).

As urban environments represent a divergence from the ancestral habitats of both humans and nonhuman animals, the neurobiological impact of the transition to city living should be carefully examined. E.O. Wilson's biophilia hypothesis posits the importance of the natural environment, including flora, fauna, weather conditions, and other variables contributing to individuals' surroundings. Considering the evolutionary importance of species maintaining close ties to the environment in order to acquire life-sustaining resources, there is little doubt that natural environments influenced the evolution of various neural functions ranging from learning to emotional responses (Wilson, 1984, 1993). Given that modern species have retained their ancestral brains, it is interesting to consider the impact of transitioning to new habitats such as urban dwellings over the course of just a few generations (Maller, 2005, Fawcett and Gullone, 2001). The identification of health-related urbanization trends is necessary to inform science- 
based policies for generating urban landscapes consistent with well-being and decreased susceptibility for psychiatric illness (Schewenius et al., 2014).

Whereas urban dwellings can provide a healthy living environment with enhanced access to important medical, recreational and cultural services and opportunities, urban environments also present disproportionate health challenges to certain components of the socioeconomic strata (World Health Organization, 2010; Anakwenze and Zuberi, 2014). Research suggests that urban living is associated with higher rates of psychiatric disorders, with rates as much as $30 \%$ higher for conditions such as mood disorders (Peen et al., 2009). The features of the urban environment that shape mental health, and the neurobiological mechanisms through which the urban environment may affect mental health are yet to be definitively determined; however, research has identified several macro-level (i.e. at the level of urban neighborhoods) and microlevel (i.e. within individuals) factors that deserved further investigation. In the current review, these macro- and micro-level factors and their potential impact on emotional well-being are considered from the perspectives of the fields of neuroscience and epidemiology. Starting with a focus on neurobiological mechanisms, animal models designed to evaluate the impact of specific elements of the physical surroundings (i.e., natural vs artificial elements), as well as the impact of increased exposure to artificial lights, will be considered. Then focusing exclusively on humans, the influence of urban sources of stress and specific genetic vulnerabilities in the development of psychiatric disorders such as posttraumatic stress disorder is reviewed. Finally, a population-level overview is provided of the types of macro-level features in the urban environment that can shape mental health, and current epidemiological strategies such as complex systems computational approaches to identify predictive factors of urban-based psychiatric illness are introduced. A consideration of such diverse data is necessary to move 
from the existing associational assumptions in this literature to eventual determination of more specific assumptions of causal inference (Pearl, 2009). Thus, these varied approaches are necessary to generate informed views about short- and long-term neurobiological effects of urbanization.

\section{The Effects of Natural and Artificial Habitats on Environmental Engagement and Emotional Resilience}

Evolutionary processes have led to animals with varying behavioral repertoires ranging from stereotyped, hard-wired responses to less prescribed, flexible behaviors. With postnatal care and the transfer of learned information occurring in warm-blooded animals, more flexible responses have emerged to facilitate the animal's requisite adaptive interactions with its frequently changing environment (Varki et al., 2009). Consequently, the importance of environmental context is considered critical in the development of neural functions; in fact, research in the field of artificial intelligence has also identified the essential role of environmental influence in the development of computer-based networks simulating mammalian CNS functions (Maniadakis and Trahanias, 2006). Thus, it is becoming increasingly clear that, in order to thoroughly understand the functions of the brain (both natural and artificial models), a clear understanding of the environment in which it operates is necessary. As various mammals have adopted habitats that differ from their ancestral ecosystems (e.g., humans transitioning to urban settings), the characteristics of environmental surroundings have been altered along several dimensions. These environmental modifications have undoubtedly impacted the neural systems of animals inhabiting evolutionarily unfamiliar terrains. In this section of the review, the 
potential impact of these environmental changes on neural and behavioral responses related to mental health and emotional resilience will be evaluated.

\subsection{The neural impact of qualitatively different environments}

At the turn of the 20th century, pioneering psychologist James Mark Baldwin emphasized the influential role of the environment in the acquisition of learned adaptations throughout an individual's life (Baldwin, 1896). Further, the more recent niche-construction perspective highlights the synergistic role of animals' interactions with the environment in modifying habitats in the continuing process of evolutionary change (Laland and Brown, 2006; Maniadakis and Trahanias, 2006). Focusing on the impact of environmental influences on the brain, Charles Darwin suggested that, based on skull measurements, the brains of domesticated rabbits were smaller than wild rabbits (Darwin, 1868). One explanation of this observation was the potential differential effects of domestic and natural environments on selection pressures impacting neural development. A similar observation was reported a few decades later when naturalist and children's author Beatrix Potter stated that the common wild mouse was "more intelligent" than the domesticated fancy breeds of mice (Lear, 2007). The notion that different environmental conditions led to short-term neural effects (i.e., within an animal's lifetime) was introduced by psychologist Donald Hebb when he reported that rats allowed to run free in his home performed better on problem-solving tasks than rats kept in standard laboratory cages (Hebb, 1949).

Neurobiological effects of varying environments were systematically investigated in the mid- $20^{\text {th }}$ century by an interdisciplinary team of scientists at the University of California, Berkeley. In these seminal studies, the environmentally complex group consisted of approximately 10 animals housed in oversized cages with enrichment stimuli, or "toys," frequently introduced to the cage. These enriched animals were compared to control animals 
maintained in standard laboratory conditions in either groups of three or, in an additional control group, housed in isolation. The rats were placed in their respective habitats at the age of 25 days and remained until they were 80 days old. Several replications of these conditions indicated that the rats in the complex environment developed a heavier cortex (especially the occipital cortex); further, the enriched animals exhibited increased levels of the enzyme acetylcholinesterase, a chemical that was positively correlated with learning ability. The impact of social enrichment itself was deemed less important than the comprehensive enriched experience (including both physical and social enrichment), although social enrichment was associated with increased subcortical weight (Bennett, Diamond, Krech and Rosenzweig, 1964). These findings were subsequently reported in mature animals, confirming that the brain had the ability to incorporate new information and adapt accordingly throughout an animals' lifespan (Simpson and Kelly, 2011).

In general, experimental enriched environments are characterized by a mixture of complex objects that stimulate multiple sensory and motor systems, as well as social interactions. With increased opportunities for motor responses, the role of increased voluntary movement has also been recognized as an important factor for neural plasticity (van Praag et al., 2000; Nithianantharajah and Hannan, 2006). The initial enriched environment studies, for example, emphasized the role of enriched experience more than the physical environment, suggesting that the animals' interactions with the environment were more influential than the mere exposure to the complex environment. Obviously, once the animals interact with the environment, it is difficult to tease apart these two aspects of environmental enrichment (Rosenzweig and Bennett, 1996). Regardless of the specific mechanisms at work in these enriched environments, research has confirmed long-term effects, including increased exploration rates and altered corticosterone 
levels later in adulthood (Pena et al., 2009), findings that emphasize the enduring effects of certain environmental parameters.

\subsection{Urban and Rural Environmental Influences}

Although enriched environments have been extensively studied, there is no consensus among protocols concerning the specific details defining the enriched environment. Parameters such as the number of animals, size of the environment, number of stimuli, and duration of exposure have varied across numerous studies (Nithianantharajah and Hannan, 2006). One variable that was initially examined, but has received little attention for the past several decades, is the origin of stimuli used in the enriched environments; specifically, if the objects were natural or manufactured, representing elements either consistent with or divergent from an animal's natural ecosystem. Although the data were never published as an individual research report, the Berkeley scientists exposed rats to a naturalistic enriched environment located outdoors and reported that this environment resulted in heavier brains than the indoor enriched animals (Rosenzweig et al., 1972).

The exposure of animals to natural elements in their environment is relevant for the topic of neural influences of urbanization considering that, compared to rural areas, natural elements are limited in urban settings. Further, when green space is available in cities it isn't always equally accessible by the city's inhabitants (Wolch et al., 2014). To further explore the impact of interacting with natural elements in one's environment, a recent investigation extended the original naturalistic enriched environment work (Rosenzweig et al., 1972) by establishing naturalistic enriched environments. In these initial studies, the same number and function of stimuli were used in natural- and artificial-enriched groups, with the difference being the origin 
of the objects - natural vs. artificial (see Figure 1). For example, a hollow log was used for shelter in the natural-enriched environment whereas a plastic igloo was used to serve the same function in the artificial-enriched environment. The preliminary results indicated that, whereas no cognitive differences were observed between the two enriched groups, biomarkers of emotional resilience such as higher levels of dehydroepiandrosterone [DHEA, associated with positive health indices (Starka et al,, 2014; Petros et al., 2013)] relative to corticosteroid levels were observed. Additionally, increased levels of exploratory behavior were associated with the natural-enriched group. Rats exposed to natural habitats also interacted with all of the elements of their environment (i.e., physical stimuli, other rats and the cage itself) more than the artificialenriched and control groups (Unpublished manuscript; Lambert et al., 2014a).

The observation that natural environmental elements have a different neurobiological impact than manufactured or artificial stimuli corroborates past findings indicating that natural stimuli have various health-promoting effects. For example, human subjects recover from stress faster following exposure to videotapes of natural settings than traffic environments (Ulrich et al., 1991). Further, the finding of increased motor activity in rats housed in natural environments corroborates findings of increased activity in rural children where the conditions are more conducive to free play (Loucaides et al., 2004). Exposure to natural environmental elements has also been associated with increased prefrontal cortex activity. Specifically, viewing an actual foliage plant resulted in increased prefrontal cortex oxy-hemoglobin concentrations compared to viewing a projected image of the same plant (Igarashi et al., 2014).

Additional research needs to be conducted, but it appears that the origin of stimuli (natural vs. manufactured) introduced in enriched environments is an important factor to consider when evaluating the impact of environmental stimuli on neural development. Although 
an emphasis has been placed on novel objects in enriched environment research over the past several decades, specific characteristics of objects may also be critical in modifying arousal levels and focused attention that subsequently affect neuroplasticity (van Praag, Kempermann and Gage, 2000; Ickes et al., 2000). Enhanced arousal in natural habitats may also lead to enhanced interaction with the environment and subsequently contribute to an animal's apparent affinity for natural environmental elements (Wilson, 1993).

\subsection{Environmental Engagement, Contingency Building and Emotional Resilience}

Several aspects of both enriched and natural environments have been associated with mental health; on the contrary, increased vulnerability to psychiatric illness has been observed in unnatural urban settings. In addition to observations of increased rates of major depression diagnoses, increased rates of schizophrenia have been observed in urban populations, with evidence of a dose-response relationship between urbanicity and onset of this mental illness (Krabbendam and Os, 2005). Heightened stress associated with city living may be one factor that predisposes urban inhabitants for the expression of symptoms of psychiatric illness. When assessed in the laboratory, subjects currently living in urban settings exhibited increased amygdala activity (involved in fear processing) during a cognitively challenging task. Further, an urban upbringing, rather than current exposure, resulted in increased activation of the anterior cingulate cortex, an area associated with emotional regulation (Lederbogen et al., 2011).

Extending beyond the nervous system, numerous reports of positive correlations between natural environments and other health indices such as immune and cardiovascular health have been reported, systems that also contribute to adaptive neural functions (Sternberg, 2009; Richardson et al., 2013). 
Any aspect of an environment that enhances an animal's effective interactions with its surroundings (e.g., enhanced attention to salient stimuli or more efficient movement) promotes the formation of contingencies between responses and outcomes. Such contingencies, and their associated neural influences, have been associated with a greater sense of control over one's environment, building resilience against symptoms associated with anxiety, stress, and the onset of depression (Lambert, 2006; Bardi et al., 2013). Rodent investigations of contingency-training require animals to dig in mounds of bedding for food rewards instead of being presented with the rewards in a non-contingent manner (Lambert, 2006). This effort-based reward model of contingency training has been associated with neurobiological evidence of emotional resilience including higher DHEA/CORT ratios and more diverse search strategies in times of cognitive uncertainty (Bardi et al., 2012, 2013; Lambert et al., 2014b). Increased activity observed in the presence of natural environments, ranging from natural-enriched laboratory environments to increased access to natural space in urban parks, can be viewed as spontaneous contingencytraining. A child engaging in "free play" establishes many response-outcome contingencies related to both physical and social environments. Accordingly, recent reports of decreased play in urban children, as well as decreased numbers of parents taking children outdoors to play each day, may lead to both short- and long-term emotional vulnerabilities in children raised in urban settings (Joens-Matre et al., 2008; Tanden, 2012; Larson, 2011). Even so, humans have identified creative ways to interact with urban environments that can also enhance responseoutcome contingencies (Decatur, 2012). Although it represents a rather extreme acclimation, Parkour, a practice of traversing urban structures such as buildings and poles with high jumps, rolls and aerial somersaults, is an example of such human adaptation to urban surroundings (Wilkensen, 2007). Regardless of the origin of the environmental stimuli, however, further 
evaluation of these varying types of environmental interactions will inform researchers about environmental elements associated with optimal engagement and mental health.

The formation of response-outcome contingencies generated by various types of environmental interactions may influence mental health by modifying self-efficacy, another variable that has been associated with emotional resilience. Whereas outcome expectancy is viewed as an estimate of a probability that a behavior will lead to a specific outcome (achieved through contingency training), efficacy expectation is the estimate that one can successfully carry out the required behavior to produce the desired outcome (Bandura, 1977). Diminished contingency and efficacy levels were associated with increased vulnerability to depression in the classic learned helplessness work (Seligman and Maier, 1967). In humans, self-efficacy is also viewed as an important mediator between depressive symptoms and stressful life events (Maciejewski et al., 2000). Interestingly, physical activity increases self-efficacy in patients diagnosed with chronic illnesses such as breast cancer and multiple sclerosis; additionally, fewer symptoms of depression were expressed in patients with higher self-efficacy scores (McAuley et al., 2010). Even in occupational settings, employers who exposed older employees to increased cognitive stimulation and novel tasks observed fewer symptoms of dementia than in similarly aged non-enriched employees (Then et al., 2013). Given these findings, any environment that increases an animal's engagement with its surroundings may lead to the establishment of adaptive response-outcome contingencies and, consequently, protection against the emergence of symptoms of mental illness.

Close ties between emotional responses and natural elements of the environment are also evident in the increased anxiety associated with specific environmental stimuli-- such as insects and heights-- that were perceived as threatening in our ancestral past (Mineka and Ohman, 2002; 
Mineka and Zinbarg, 2006). This predisposition toward certain environmental components of our evolutionary past confirms the long-lasting environmental effects on the nervous system that are further influenced by the day-to-day interactions between mammals and their environments. However, even these predisposed fear responses can be altered by short-term environmental enrichment in male rats (Mitra and Sapolsky, 2012). Given these multiple environmental inroads to the lifelong development of the nervous system, specific characteristics of the animals' surroundings are important to consider in the exploration of various models of mental health, ranging from the housing regulations of laboratory animals to policies regulating green space in cities.

\subsection{Conclusion}

The initial enriched environment studies conducted a half century ago have slowly changed the perception of the neural landscape once thought to be relatively inflexible throughout one's lifetime. The emphasis on the environment continues to be important for obtaining a thorough understanding of how the brain adapts to various changing environments to enhance survival. As modern human environments stray from our ancestral roots, a close examination of how these modifications impact neural responses and functions may illuminate causal factors for various mental illnesses, especially those that are expressed at increased rates in urban settings.

Insert Figure 1 


\section{Effects of light pollution on neuroinflammation and mood}

\subsection{Light at Night}

The temporal pace of cities has changed dramatically over the past 200 years. Prior to the early 1800s night was a formidable constraint on human activities. People are diurnal, and relatively blind at night. Prior to the use of gas, then electric, street lights, all legitimate human business stopped at sunset. As Roger Ekirch describes in his excellent book, At Day's Close: Night in Times Past, (Ekirch, 2006), night was to be feared because of criminals, fires, emptied chamber pots, spooked horses, and even the supernatural. All respectable people, not just children, feared the dark. Prayers and other incantations were used to get through it. As gas lights became available, initially indoors, then outdoors, it became fashionable for people of wealth to venture out for night-time social activities in large cities such as Paris and London. This practice was soon imitated by the less privileged classes, which required additional street lighting. Illuminating the night via electric lights permitted large-scale social and work activities, and the development of electric lights soon led to widespread illumination of cities, towns, and even small villages.

Cities produce visually amazing nighttime skies that can even be seen from space (Figure 2). Since the advent of electric lights around the turn of the $20^{\text {th }}$ century, people have become increasingly exposed to relatively bright and unnatural light at night, both outside and inside their homes. This "light pollution" now affects $99 \%$ of the US and European population and $\sim 60 \%$ of the remaining world's population (Navara and Nelson, 2007). Electric lighting was a boon for developing industry and technology; light at night permitted work into the night, which 
drove economic development. Use of light at night continues to rapidly increase $(6 \%$ increase per year) without thorough [or any] consideration of its biological implications (Fonken and Nelson, 2011).

Most consider light at night to be an innocuous, if not beneficial, environmental factor of modern life, which is likely why it was overlooked as a significant health risk factor until recently. However, because of the dramatic effects that light has on the endogenous circadian system (McClung, 2007; 2011) and upon downstream outputs such as hormone secretion, light at night exerts a significant effect on many physiological processes (Stevens, et al., 2013a). It is now evident that light at night has marked social, ecological, behavioral, and health consequences (Bedrosian and Nelson, 2013). In this section, the growing research on the maladaptive influences of light at night on brain function, especially affective responses is reviewed.

\subsection{Effects of Light at Night on Humans}

Epidemiological studies report that depression rates are elevated among city dwellers compared to people living in rural regions (Stevens et al., 2013a). Although elevated depression rates are associated with urban life, we do not fully understand the factors underlying this association. Some of the disparity obviously reflects differential access to mental health care and differences in the rate of undiagnosed depression. However, the alternative hypothesis that increased exposure to light at night among city dwellers disrupts brain circadian rhythms leading to impaired affective responses has not been ruled out. For instance, the Old Order Amish living in the US do not use electricity and thus are not typically exposed to significant levels of light at night. The incidence of major depressive disorder (MDD) is $\sim 1 \%$ among the Amish (Egeland and Hostetter, 1983) — the same rate of depression reported mid-20 ${ }^{\text {th }}$ century for the 
general US population — compared to current rates of MDD, which are estimated to be $\sim 15 \%$ of the general population (Riolo et al., 2005). Again, other lifestyle factors may contribute to better mental health in this population, but the Amish also have lower rates of cancers, obesity, cardiovascular disease, metabolic syndrome, and Type 2 diabetes, disorders all linked to exposure to light at night and night shift work (Westman et al., 2010; Stevens et al., 2013a).

Shift workers may serve as 'canaries in the coal mine' warning us of the dangers of deranged circadian rhythms on mood; indeed, several studies of shift-workers have linked night work to depressed mood. Continual shift work has detrimental effects for sleep and social interactions, and is correlated with high prevalence of MDD, especially among women $(22.6 \%$ of female shift workers versus $13.4 \%$ of male shift workers; Scott et al., 1997). The effects of shiftwork are often reported soon after onset. For example, student nurses working the night shift for the first time reported feelings of helplessness, loss of control, apathy, and low social support after just 90 days (Healy et al., 1993). Prolonged night shift work increases lifetime risk for MDD even after night shifts are discontinued (Scott et al., 1997). Proposed treatment for night shift work is bright light exposure during the night and black-out curtains or sleep masks during the day to phase shift the biological clock to align with the work schedule, thus improving alertness at work and facilitating sleep during the day (Czeisler et al., 1990). This approach has had limited success because of the difficulty maintaining such a schedule; during weekends and other non-work nights, night shift workers quickly re-synchronize with dominant environmental and social cues.

Although elevated depressive symptoms are well documented among shift workers (Healy et al., 1993), these studies do not rule out other variables involved, such as sleep disruption and episodic (e.g., weekend) phase shifts. It is difficult to obtain direct data linking 
light at night to mood in human subjects because such studies would entail careful control of several environmental variables over many weeks.

One excellent correlational study that could serve as an example for studies of light at night on mood examined the effects of city lights on the rate of breast cancer in women. By comparing the average light levels from the U.S. Defense Meteorological Satellite Program with the neighborhoods of recently diagnosed breast cancer patients, a strong correlation was observed between light at night and breast cancer incidence in $~ 150$ Israeli communities (Kloog et al., 2008). Other relevant socio-economic correlates did not account for this link. The authors suggested that women living in the darkest communities might produce prolonged durations of nightly melatonin lowering risk of breast cancer. A similar link may exist between depression and nightly light levels, but this remains unexamined.

\subsection{Effects of Light at Night on Nonhuman Animals}

Nonhuman animal models allow mechanistic studies into the role of light at night in mood regulation, without the confounding variables associated with human studies. In one early study of the effects of light at night, male mice were housed in either standard light-dark cycles or in constant light (Fonken et al., 2009). Mice either had access to an opaque tube, which allowed them to escape the light, or a clear tube that prevented light escape. After 3 weeks mice were tested in standard assays of depressive-like responses for rodents, viz., Porsolt forced swim and sugar anhedonia tests. Mice housed in constant light drank less sugar water indicating an anhedonic response, which models aspects of human depression. This response was partially reversed by allowing mice to escape the nightly light.

Although potentially informative, these results are limited by several factors. First, people are generally not exposed to continuous bright lighting for $24 \mathrm{~h}$ per day. The mice 
exposed to continuous light throughout the day and night had no temporal cue to establish time of day and their circadian rhythms were likely free running. Second, unlike humans and most other mammals, most inbred laboratory mouse strains do not produce melatonin. The extent to which melatonin is implicated in the effects of light at night on mood (as it is on cancer; Blask et al., 2005) remains unspecified (although increased depressive-like responses to light at night were reported in a strain of mice that lacks melatonin; Fonken et al., 2009). Finally, unlike humans, most rodents are typically nocturnal; light at night coincides with their active period, whereas light at night occurs during the inactive period when people typically sleep. Indeed, many of the negative health effects of light at night are attributable to sleep disruption. Studies of nocturnal rodents are valuable because of the ability to separate the effects of light at night from disrupted sleep; sleep is not significantly affected by light at night in mice (Borniger et al., 2013). Examination of one diurnal rodent species, African Nile grass rats, revealed that light at night affects mood and cognition; however, sleep quality was not investigated in this species, so it remains possible that light at night has its effects on mood via sleep disruption or some other circadian mechanisms (Fonken et al., 201).

To address some of these issues, an animal model (female Siberian hamsters) was developed to examine the effects of dim (5 lux) light at night. This light intensity is similar to levels easily encountered by people through the use of nightlights, televisions, computers and ereaders at night. It is important to examine females because depression rates are elevated among women compared to men. Hamsters exposed to 5 lux of light at night entrain to the light-dim light cycle, at least in terms of locomotor activity, although homecage locomotor activity is slightly reduced during the dim light phase compared with typical dark phase activity levels. Returning the animals to dark nights quickly reverses this effect (Bedrosian et al., 2013b). 
Entrainment of other circadian rhythms may also be influenced by exposure to dim light at night; e.g., the amplitude of daily expression patterns of core clock proteins, PER1 and PER2, in the SCN are dampened by exposure to light at night, although BMAL1 remains unchanged (Bedrosian et al., 2013b). Daily cortisol rhythms are also dampened (Bedrosian et al., 2013b). Studies of female hamsters have consistently reported that dim light at night provokes depressive-like responses similar to male mice (Bedrosian et al., 2011; 2012; 2013b). After just 4 weeks of exposure to dim light at night, hamsters are more immobile in the forced swim test, typically interpreted as behavioral despair, and reduce preference for sucrose solution (Bedrosian et al., 2012; 2013a). Within two weeks of eliminating dim light at night, however, responses in both of these tests are similar to hamsters exposed to dark nights (Bedrosian et al., 2013b). Similarly, two weeks of treatment with the selective serotonin reuptake inhibitor, citalopram, ameliorates the light at night-induced depressive-like symptoms, supporting the validity of this model (Bedrosian et al., 2012).

Understanding the mechanisms underlying these behavioral responses is incomplete, but morphological changes in the hippocampus, a brain structure implicated in the pathophysiology of MDD, are associated with the affective responses and clock gene changes. Indeed, depressed patients often have hippocampal atrophy (Frodl et al., 2002; Sheline et al., 1999; Bremner et al., 2000) and dysregulation of many hippocampal-associated systems, such as stress coping and memory (reviewed in Nestler et al., 2002). Similarly, loss of hippocampal dendritic spines and reduced dendritic complexity are observed in animal models of chronic stress and depression (Hajszan et al., 2005; 2009; 2011). In these models, hippocampal expression of brain-derived neurotrophic factor (BDNF) is typically reduced, whereas treatment with antidepressant drugs enhances BDNF expression (Duman and Monteggia, 2006). Hamsters exposed to 4 weeks of 
dim light at night (LAN) reduced BDNF mRNA expression and reduced dendritic spine density on hippocampal CA1 pyramidal neurons (Bedrosian et al., 2013b). Again, both of these effects are reversed after eliminating returning the animals to dark nights within 2-4 weeks.

Because of relatively high numbers of proinflammatory cytokine receptors (e.g., interleukin (IL)-1b and tumor necrosis factor (TNF)- $\alpha$, the hippocampus is disproportionately vulnerable to inflammation compared with other brain regions (Maier and Watkins, 1998). Neuroinflammation may play a role in depressive-like behavior provoked by many types of circadian disruption (reviewed in Bedrosian and Nelson, 2013). Female hamsters exposed to dim light at night increase tumor necrosis factor- $\alpha$ expression in the hippocampus; treatment with a pharmacological inhibitor of TNF- $\alpha$ prevents behavioral depressive responses in response to light at night (Bedrosian et al., 2013b). This link between depression-like behavior provoked by circadian disruption and neuroinflammation is consistent with the proposed role of proinflammatory cytokines and circadian disruption in the pathogenesis of depression (Narasimamurthy et al., 2012).

Thus, exposure to dim light at night might alter mood by disrupting circadian rhythms, leading to changes in neuroinflammation. However, a recent study examined whether unnatural light exposure can directly impair mood; this experimental paradigm does not strongly influence circadian timing or sleep (LeGates et al., 2012). Mice were exposed to an alternating cycle of 3.5 $\mathrm{h}$ of light and $3.5 \mathrm{~h}$ of dark (termed T7); this light cycle lengthens the period of body temperature and locomotor activity rhythms, but maintains diurnal fluctuations in SCN PER2 expression in and total sleep. After 2 weeks of exposure to these T7 cycles, mice increased depressive-like responses in the forced swim and sucrose preference tests. Additionally, the T7-exposed mice reduced hippocampal long-term potentiation and impaired performance on learning and memory 
tests (LeGates et al., 2012). Mice lacking the gene for melanopsin failed to show these responses to the $\mathrm{T} 7$ cycles suggesting that the intrinsically photoreceptive retinal ganglion cells (ipRGC) projections mediate the responses directly because ipRGCs project to mood-regulating regions of the brain, both directly and via the SCN (Hattar et al., 2006).

Taken together, the animal work suggests that light at night impairs mood regulation. An important question arising from this collective work is how to prevent the deleterious effects of light at night when exposure cannot be avoided (e.g., night shift workers). One possibility may be to manipulate the wavelength of light exposure. As mentioned, the melanopsin-expressing ipRGCs responsible for projecting light information to the circadian system are minimally responsive to red (long) wavelength light. Replacing standard bulbs with ones emitting long wavelength light where possible, or using glasses that only transmit long wavelengths, may be an effective preventative treatment against the disruptive effects of light at night in people. Animal studies support this recommendation. For example when hamsters were exposed to dim red, blue, or white light at night, fewer depressive-like responses were observed in animals exposed to red compared to white or blue light (Bedrosian et al., 2013c).

\subsection{Conclusion}

Based on animal studies, the mood depressing effects of light at night can be prevented by (1) treatment with selective serotonin reuptake inhibitors, (2) blocking neuroinflammation in the brain, (3) turning off the lights, or (4) changing the quality of the light to longer wavelengths. Thus, relatively low-cost manipulations such as using black-out curtains to block out street lights and turning off extraneous lights and removing all light sources in the sleeping quarters including televisions and computers can reduce the effects of environmental lighting at night on health.

The background light of e-readers can be adjusted to longer wavelength light or wearing goggles 
designed to block out blue wavelength lighting may prevent light induced melatonin suppression. Furthermore, work environments could potentially use lighting sources that emit less blue light, which is at odds with the adoption of energy-saving compact fluorescent bulbs. Cities could install streetlights that prevent light scatter and have less disruptive long wavelength lights.

City life now functions on a 24-hour-a-day schedule. Although there are many economic and other societal benefits to such a schedule, converging evidence from epidemiological and experimental work suggests that light at night has unintended, maladaptive consequences on mood. In many ways, this field of study is just beginning; further characterization of the effects of light at night is required, as well as development of effective interventions to ameliorate the unintended negative effects of light at night on health (Fonken and Nelson, 2011; Bedrosian and Nelson, 2013).

Insert Figure 2

\section{Violence in the City: Biomarkers in Children and Adults}

A large number of studies indicate that individuals living in urban environments are at high risk for exposure to traumatic events and posttraumatic stress disorder (PTSD) ( Breslau et al., 2004; Schwartz et al., 2005; Switzer et al., 1999), which is the fourth most common psychiatric diagnosis, affecting $10 \%$ of all men and $18 \%$ of women (Breslau et al., 1998). Urbanization in itself can lead to increased rates of trauma exposure due to higher concentrations of poverty, substance abuse, and crime (Anakwenze and Zuberi, 2013). For example, a recent study in Baltimore found a $65 \%$ rate of lifetime trauma exposure and a 33\% rate of PTSD (Alim et al., 2006). Recent studies of random sampling of an inner-city Atlanta population at a state-funded 
hospital, as part of a large genetic epidemiological study entitled Grady Trauma Project, found $88 \%$ prevalence of exposure to any significant trauma and $46 \%$ of lifetime PTSD ( Gillespie et al., 2009). In such samples, exposure to trauma may begin early in life; studies of children and young adults from similar samples suggest that initial trauma exposure during childhood or adolescence is common (Schilling, Aseltine and Gore, 2007). In the Grady Trauma Project, approximately one fifth of the samples have had significant exposure to childhood trauma ( Gillespie et al., 2009).

According to the Diagnostic and Statistical Manual of Mental Disorders, $5^{\text {th }}$ edition (DSM-5), PTSD is characterized by four major symptom clusters following an event that elicited fear, helplessness, or horror. The first category includes symptoms of traumatic event reexperiencing, such as intrusive thoughts, nightmares, and flashbacks; phenomena that are often induced by reminders of the event. The second cluster is associated with avoidance of stimuli associated with the traumatic event. The third cluster involves negative affect, and includes loss of interest in social interactions and detachment. The final category describes trauma-induced physiological alterations such as increased startle and hyper-arousal including tachycardia, elevated perspiration, and shortness of breath.

The heterogeneity of PTSD implicates the involvement several divergent neural systems in the underlying neurobiology of PTSD symptomatology (Frewen and Lanius, 2006); in addition, individual differences in one's neurobiological makeup may also contribute to the variability observed in patient presentations following trauma exposure (Yehuda et al.,1997). Defining such neurobiological intermediate phenotypes that reflect both the biological underpinning and clinical symptoms has the potential to move the field forward in better understanding and treatment of PTSD. Such intermediate phenotypes also provide a useful 
measure for genetic studies; historically, the genetic risk for PTSD has been difficult to ascertain given that very large sample sizes are required to capture such a heterogeneous phenotype. However, in a recent study of 1,237 individuals from the Grady Trauma Project, results indicated that a single polymorphism (SNP) in the gene coding for the pituitary adenylate cyclaseactivating polypeptide (PACAP) was associated with higher symptoms of PTSD in women, but not men (Ressler et al., 2011). Specifically, the CC genotype of the ADCYAP1R1 gene coding for the PACAP receptor appeared to increase risk in females. This finding is of great importance since PTSD is two to three times more prevalent in women, but the mechanisms of this differential risk are poorly understood.

\subsection{Brain Response to Fear}

Fear responses provide observable neurobiological phenotypes - such phenotypes are advocated by Research Domain Criteria (RDoC) of the National Institutes of Mental Health. Neuroimaging studies have shown that the brain structures that are activated in response to fearful stimuli, such as the amygdala, show hyperactivation in PTSD subjects compared to controls (Liberzon and Martis, 2006; Shin, Rauch and Pitman, 2006). Our studies with women who survived urban trauma showed greater amygdala activation during a functional magnetic resonance imaging (fMRI) task in which they watched fearful compared to neutral facial expressions. Moreover, women who had PTSD had higher amygdala activation than women with trauma but who did not currently have PTSD ( Stevens et al., 2013b). Figure 3a shows the difference in amygdala activation between these two groups. Several studies have indicated that exaggerated amygdala activity during fearful stimulation is coupled with reduced top-down control of the amygdala by the prefrontal cortex (PFC) (Liberzon and Martis, 2006; Liberzon et al., 1999; Rauch, Shin and Phelps, 2006; Rauch et al., 2000; Shin et al., 2004). Recent meta- 
analyses of imaging studies during emotion processing in PTSD, social anxiety, and specific phobia indicated that the rostral ACC is less active in PTSD patients relative to controls; an effect not found in other anxiety disorders (Etkin and Wager, 2007). Additional findings suggest that hyperactivation of the amygdala may be a genetic vulnerability: the same SNP that was associated with PTSD risk in women was also related to higher amygdala activity in response to fearful faces ( Stevens et al., 2014). The women who carried the CC genotype of the ADCYAP1R1 gene had much higher activation than women with the non-risk genotype, see Figure $3 \mathrm{~b}$. As depicted in the figure, the effect of the gene was more robust than the disorder itself-an indication that risk can be overcome.

\subsection{Fear Conditioning}

PTSD patients also show an inability to inhibit fear conditioned responses in the presence of safety; impaired fear inhibition may be a specific biomarker of PTSD ( Jovanovic et al., 2010). Fear conditioning is based on a simple Pavlovian conditioning model in which a neutral conditioned stimulus (CS, for example, a light) is paired with an aversive unconditioned stimulus (US, for example, electric shock). After a number of pairings, the association is formed so that the CS alone elicits the conditioned response (CR, for example, a fear response). This basic model is used in animal as well as human research to investigate mechanisms of fear acquisition. In humans, the acoustic startle response provides an ideal translational tool to investigate fear conditioning, since the amygdala is directly connected with the startle circuit (Davis, 1992; Grillon and Morgan, 1999). Fear-potentiated startle (FPS) is the relative increase in the startle magnitude elicited in the presence of a conditioned stimulus (CS+) that was previously paired with a US; this psychophysiological measure can be used to index both the increase in fear during conditioning, as well as the reduction of fear during extinction, which is the repeated 
presentation of the CS without the US. Extinction provides a laboratory analog of exposure therapy; thus developing methods that enhance extinction may also facilitate exposure-based therapies for PTSD. Several studies have found that urban trauma results in exaggerated fear expression and impaired fear extinction in PTSD subjects ( Jovanovic and Norrholm, 2011; Jovanovic et al., 2010; Norrholm et al., 2011).

In addition to conditioned fear, researchers have also found that darkness, which is an innate (unconditioned) anxiogenic cue, increases startle response in a sex-specific way, i.e. women with PTSD show greater dark-enhanced startle than men (Kamkwalala et al., 2012). As was the case with fMRI, fear-potentiated startle to safety signals, i.e., poor discrimination between danger and safety, and dark-enhanced startle were higher in women who carried the CC genotype for the PACAP receptor gene (Ressler et al., 2011).

\subsection{Biomarkers of Fear in Children}

As mentioned above, low-income urban environments are associated with high rates of childhood trauma (Gillespie et al., 2009), often due to neighborhood violence or criminal activity (Wade et al., 2014). There is a growing body of literature on physiological outcomes in children at risk for psychopathology. One of the only longitudinal studies of such vulnerability traits in offspring of probands with anxiety disorders found that high-risk offspring had greater autonomic reactivity and increased startle responses compared to low-risk offspring (Merikangas et al., 1999). Baseline, dark-enhanced startle, and fear-potentiated startle have indicated that these measures may serve as good predictors of risk for psychopathology in children (Grillon et al., 1997). A recent study by Pine and colleagues examined fear-potentiated startle in behaviorally inhibited adolescents and found that anxiety was associated with increased fearpotentiated startle to the safety cue, indicative of fear overgeneralization (Reeb-Sutherland et al., 
2009). Recent investigations of fear-potentiated startle in children revealed that discrimination between danger and safety signals develops around age 10, and that anxiety interferes with normal development ( Jovanovic et al., 2014). However, very little work has focused specifically on the effects of urban trauma on child development.

In addition to direct environment, maternal factors can significantly contribute to child risk. There is evidence that maternal psychopathology, stress, and trauma exposure affect parenting practices and the quality of mother-child interactions. For example, parental trauma exposure significantly relates to decreased parenting satisfaction, punitiveness, psychological aggression, and the likelihood that child protective services reports will be filed (Banyard et al., , 2003). In a study of dark-enhanced startle in school age children we found that maternal history of child abuse increased startle responses in her children after controlling for her PTSD and depression symptoms ( Jovanovic et al., 2011). These effects were independent of the child's own exposure to trauma but were predicted by the mother being a victim of physical abuse in her childhood, many years prior to the pregnancy.

\subsection{Transgenerational Effects}

Stress-related disorders tend to be perpetuated across generations, so that children with mothers who are depressed or anxious are at higher risk of developing anxiety and depression themselves (McClure et al., 2001). Furthermore, the literature suggests familial aggregation of anxiety disorders (Cooper et al., 2006; Last et al., 991; McClure et al., 2001), including PTSD (Sack et al., 1995; Yehuda and Bierer, 2008; Yehuda et al, 2001). The elevated risk in offspring of parents with PTSD is not fully attributable to increased levels of trauma exposure (Dulmus and Wodarski, 2000; Sorscher and Cohen, 1997; Yehuda and Bierer, 2008; Yehuda et al., Brynes, 1998), and there are several other putative mechanisms for the observation of 
transgenerational effects. It is possible that one of the behavioral mechanisms by which mothers with PTSD transmit the disorder to their children is through direct maltreatment. Maternal PTSD is associated with higher rates of physical and emotional abuse of offspring (De Bellis et al., 2001), which are in turn strong predictors of PTSD in adulthood (Binder et al., 2008; Nemeroff et al., 2006; Yehuda et al., 2007). Alternatively, mothers with PTSD may create adverse environments that increase risk of child anxiety through unstable family structure ( Bada et al., 2008; Collishaw et al., 2007) or pre- or postnatal substance abuse (Bada et al., 2007; Luthar and Sexton, 2007).

In addition to the environmental variables, there are putative biological mechanisms for increased risk for PTSD in children of mothers with PTSD. One such mechanism is shared genotype. As discussed above, we found that women with the CC genotype of the PACAP receptor gene have higher PTSD symptoms, as well as higher fear responses and greater darkenhanced startle. Children who carry the same risk alleles of this SNP also show exaggerated startle responses in the dark vs light compared to children with the non-risk genotype (Jovanovic et al., 2012). Interestingly, pre-pubertal children do not exhibit the sex specific effects seen in adults - the risk genotype increases dark-enhanced startle in both girls and boys. Because this particular SNP is part of an estrogen response element, it is likely that its effects change during puberty.

Another potential mechanism for transgenerational effects is epigenetic transmission. A recent animal study showed that fear conditioned responses can be transmitted to first and second generation offspring through epigenetic modifications (Dias and Ressler, 2014). DNA methylation at cytosine-guanine dinucleotides ( $\mathrm{CpG}$ sites) is the epigenetic modification that is most commonly studied in humans. While it is still unclear whether cross-generational 
mechanism operate in humans, there is evidence showing that childhood trauma exposure has long-term effects on DNA methylation (Klengel et al., 2013). Given the longevity of these effects it is possible that they could be carried over into the next generation.

\subsection{Conclusion}

In summary, we have shown that brain imaging and startle response provide potential biomarkers of trauma exposure and PTSD, and that these biomarkers are associated with genetic risk and environmental variables. The fear circuitry in the brain shows higher activation in individuals who have risk genotypes and inner-city exposure to violence. Furthermore, these genetic and environmental factors transcend generations so that the next generation shows the same fear-related dysregulations as the parental generation, making urbanization a significant and long-term public health problem. Understanding such brain-related biomarkers is of utmost importance to progress in this field, and in breaking the cycle of urban violence and PTSD.

Insert Figure 3

\section{Translating animal research to humans: A population-level lens on the urban environment and brain disorders}

\subsection{Population-level patterns of brain disorders in urban vs. rural environments}

There has long been an interest in comparing population patterns of brain disorders in urban versus rural areas ( Breslau et al., 2014; Kessler et al., 1994; Kessler et al., 1995; Peen, et al, 2010). Such population-based studies have focused on phenotypic manifestations of brain disorders - that is, a set of symptoms that reflect an emotional and behavioral pattern consistent 
with an underlying psychiatric disorder. In this section of the review, a macro-level lens is applied to population patterns of brain disorders in urban environments. Further the discussion shift from a discussion of the influence of urban environments on direct measures of brain function, to a discussion of ways that specific features of urban contexts influence symptom manifestations of phenotypes in humans, as established by the American Psychiatric Association's Diagnostic and Statistical Manual of Mental Disorders (American Psychiatric Association, 2000). Consequently, the focus in this section is on mood and anxiety disorders, which have clear underlying brain pathology, and pose the highest population-level burden of disease among all brain disorders (Grant et al., 2004).

\subsection{How can the urban environment shape mood and anxiety disorders?}

Recent studies have tried to identify specific features of the urban environment that give rise to mood and anxiety disorders. Such research has focused on intraurban differences in disorders across neighborhoods, and has considered the contribution that socioeconomic characteristics of local neighborhoods, the physical environment, and the social interactions that are shaped by the urban experience, make to psychiatric disorders ( Galea, 2011). The majority of these studies have focused on depression, and to a lesser extent on general symptoms of anxiety or posttraumatic stress disorder( Mair et al., 2008).

Neighborhoods characterized by greater socioeconomic disadvantage have been consistently found to have higher rates of psychiatric disorders (Beard et al., 2009; Diez et al., 2010; Galea et al., 2007; Kubzansky et al., 2005; Mair et al., 2010; Silver et al., 2002; Wight et al, 2010) There are multiple pathways through which disadvantaged neighborhoods may increase the risk for depression; here we discuss four illustrative examples. First, neighborhoods 
with higher rates of poverty likely expose residents to multiple stressors, such as crime, physical and social disorder, and social isolation, which interact to worsen symptoms of mood disorders such as depression and increase anxiety ( Galea et al., 2007). Second, neighborhood disadvantage can affect the level of social organization and investment in the neighborhood (Sampson et al., 1997). Neighborhoods with lower levels of social organization have limited capacity to advocate for health services and resources for individuals with mental health needs, and have weaker social support networks to protect individuals from worsening problems of mood and anxiety (Blair, 2014; Cutrona et al., 2005). Third, neighborhood disadvantage can affect the resiliency or vulnerability individuals have to stressors and negative life events, which can put them at greater risk for mood and anxiety disorders (Beard et al., 2009). Fourth, residents of disadvantaged neighborhoods are exposed more often to drug activity, which is associated not only with increased drug use, but also increased risk for mental health problems that develop subsequent to drug use (Furr-Holden et al., 2011; Galea et al., 2003; Galea et al., 2004; Galea et al., 2005).

Several features of the physical environment may also shape the intraurban distribution of mood and anxiety disorders. As previously described, access to green space has been proposed as a resource that can alleviate stress; additionally, access to green spaces can encourage social engagement in urban neighborhoods (Astell-Burt et al., 2014; Beyer et al., 2014; de Vries et al., 2013; Roe et al., 2013). Further, neighborhoods characterized by more densely populated and vibrant streets, including mixed land use, availability of destinations for daily living and street connectivity are more walkable and can promote social engagement and contact (Miles et al., 2012; Saarloos et al., 2011). In contrast, deterioration and disorder of the urban environment, including graffiti, litter in the streets, and dilapidated buildings can have a direct effect on mood 
and anxiety disorders by increasing the level of fear and lack of perceived control in local neighborhoods, and it can also reflect deteriorated neighborhood conditions (Gapen et al., 2011; Ross and Mirowsky, 2001).

The social fabric of urban neighborhoods may be an important driver of mood and anxiety disorders. The higher population density of urban neighborhoods, coupled with residential turnover due to population migration into and between urban neighborhoods, can affect the level of social cohesion among neighbors, and neighborhood collective efficacy, defined as the capacity of neighbors to work together to achieve common goals to improve the neighborhood ( Galea, 2011; Sampson et al., 1997). Social cohesion and collective efficacy have been proposed as protective buffers against psychiatric disorders, as they contribute to broader support networks, generate a greater sense of trust, and allow people to feel greater control over their living environments (Blair, 2014; Latkin and Curry, 2003; Stafford et al., 2011). Social cohesion and collective efficacy have been associated with lower rates of depression in urban neighborhoods, ( Ahern and Galea, 2011; Echeverría et al., 2008; Gary et al., 2007; . Mair et al., 2010) as well as with lower rates of posttraumatic stress disorder (Gapen et al., 2011; Johns et al., 2012; Lowe et al., 2014; Ursano et al., 2014).

\subsection{The next step: Generating effective intervention strategies}

Population-level studies have revealed potential local mechanisms in urban neighborhoods that may shape the distribution of mood and anxiety disorders within cities. The next step then, is to determine how to intervene in urban neighborhoods to interrupt the previously described associations between local socioeconomic, physical and social features of urban habitats and increased population rates of mood and anxiety disorders. 
The literature suggests there are several aspects of the urban environment that, if modified, could have an impact on population levels of mood and anxiety disorders, including: reducing the concentration of poverty, increasing green space and improving the walkability of urban areas, and strengthening social cohesion and social control in local neighborhoods. However, there remains a substantial inferential leap from observational data suggesting that there are neighborhood influences on the risk of mood and anxiety disorders to confidence that manipulating neighborhoods can substantially reduce the prevalence of mood and anxiety disorders (Kaufman et al., 2003; Pearl, 2000; Shafer, 1995). Observational studies have difficulty distinguishing differences in neighborhood characteristics from differences in the types of individuals residing in neighborhoods (Oakes, 2004; Oakes and Kaufman, 2006)- this is a particular concern in the case of mood and anxiety disorders, since some evidence exists that psychiatric disorders lead to downward drift into worse neighborhoods (Freeman and Alpert, 1986).

To address this challenge there has been a growing investment in randomized social interventions to evaluate the impact of local interventions in urban neighborhoods on health, including on mental health (Leventhal and Brooks-Gunn, 2003). However, randomization of urban environments is not without its own challenges, (Kaufman et al., 2003) including the impossibility of randomization to certain exposures, resource constraints, ethical issues, and long latency periods between social exposure and the onset of symptoms. Further, existing experimental evaluations of urban interventions have focused on only one intervention in isolation, limiting our understanding of the relative effectiveness and cost of investing in different types of interventions - alone or in combination. Finally, experimental approaches attempt to isolate the effect of changing a single factor while keeping the rest of the system 
constant - this type of design constrains the replicability of study findings, as it does not consider the complexity of the urban system that affects the effectiveness of an intervention. Experimental (and for that matter, observational, regression-based) approaches are not able to adequately and simultaneously consider dynamic, feedback relations between multiple features of the urban system, the role that interactions between individuals plays in shaping population patterns of disease, or the nonlinear relations between different components of the urban system.

\subsection{Using complex systems approaches to identify promising intervention strategies in urban neighborhoods}

There is an increasing recognition that we need methods that identify and incorporate the complexity of social systems in order to better understand and intervene on the urban environment to improve health (Diez et al.,2010; Galea, 2011). Hence, complex systems methods such as agent-based models are increasingly used as a complement to existing observational and experimental studies. Complex systems approaches involve the use of computer-based algorithms to model dynamic interactions among individuals and between individuals and their environment ( Galea et al., 2009; Galea et al., 2010).

In this section, agent-based models (ABMs) are evaluated; ABMs refer to a type of complex systems approach, in which agents with a specified set of features interact with each other and their environment according to a set of prescribed rules, and are able to adapt their behavior based on changes in their environment, their past history and interactions with other agents (Bonabeau, 2002). Emerging population-level patterns can be compared under different behavioral rules and in agent populations with different characteristics (Epstein, 1999; Epstein 
and Axtell, 1996). Agents are allowed to be heterogeneous and autonomous and reciprocal relations between exposures and outcomes can be explicitly modeled in the system.

This type of approach offers a promising tool to refine hypotheses about the types of interventions in the urban environment that may be worth testing in community randomized trials (Auchincloss and Roux, 2008; Galea et al., 2009). By establishing prescribed rules about the characteristics of simulated individuals (i.e., agents), their networks, contexts, and behaviors, investigators can simulate scenarios where only one aspect of the initial conditions is changed, given an underlying and specified context of complexity, and thus conduct counterfactual urban policy experiments without issues of resource costs or ethical concerns.

A simulation of the impact of neighborhood interventions on racial/ethnic inequalities in violence serves as an illustration of the potential offered by complex systems approaches such as ABM. Violence disproportionately affects urban Blacks: in 1980-2008, Blacks were 6 times more likely to die from homicide than Whites, and the rate of violent offending was 8 times higher among Blacks than among Whites (US Department of Justice, 2011). Mobilizing collective efficacy in urban neighborhoods has been proposed as a strategy to reduce rates of violent offending and victimization (Sampson et al., 1997), as it has been consistently associated with reduced neighborhood victimization across observational studies in the United States and other countries (Ahern et al., 2013; Morenoff et al., 2001; Sampson et al., 1997; Sampson and Wikstrom, 2007; Simons et al., 2005).

Recently, researchers simulated an agent population consisting of 4000 adults that matched the New York City population and further evaluated the impact that mobilizing collective efficacy had on racial/ethnic disparities in violent victimization in two different types 
of hypothetical contexts: (1) complete residential segregation by race; and (2) no segregation by race and income (see Figure 4; Cerda et al., 2014). Results indicated that increasing collective efficacy by a small amount for the entire population effectively reduced the population prevalence of victimization (Cerda et al., 2014). However, assuming a context of residential segregation by race (which most closely resembled the observed New York City context), collective efficacy experiments benefitted Whites more than Blacks, preserving racial inequalities in victimization (Cerda et al., 2014). The only way to reduce Black-White inequalities in victimization was to reduce residential segregation.

In this case, ABM allowed researchers to answer questions about the effectiveness of community-level experiments that we could not have answered with observational data or with real-life experiments. Through simulations, these researchers were able to enact a series of counterfactual experiments, reflecting different doses of collective efficacy, at different durations, assuming different patterns of racial and economic residential segregation. Because of existing patterns of residential segregation, it was not possible to randomize the same population to such an experiment under different segregation patterns. This is just one example of the ways that complex systems approaches can be used to answer new questions about the role the urban environment plays in shaping key drivers of mood and anxiety disorders.

\subsection{Conclusion}

Research suggests that populations living in urban environments may be at increased risk for mood and anxiety disorders. Key features of the urban environment have been shown to matter for psychiatric illness, including socioeconomic features of the neighborhood such as concentrated poverty, features of the physical environment such as access to green space, and the 
social fabric that characterizes urban neighborhoods. A critical unanswered question concerns how to strategically intervene in urban neighborhoods to interrupt the observed associations between exposure to local socioeconomic, physical and social features of an urban environment and increased population rates of mood and anxiety disorders. Complex systems approaches provide a tool to identify promising avenues for intervention before investment is made in largescale randomized community trials.

Insert Figure 4

\section{Concluding Remarks}

Compared to rural environments, multiple aspects of urban habitats may lead to increased vulnerabilities for maladaptive neurobiological functions and the consequent emergence of psychiatric illness. Considering that, in many ways, urbanization represents an evolutionary mismatch between contemporary brains and the neural systems of our human ancestors, an increased vulnerability for psychiatric illness may represent an escalating medical threat as urban populations are projected to rise in future years (Hidaka, 2012; Seto et al., 2012). Although many factors have been associated with urbanization effects, the following were considered in the current review: (1) exposure to artificial, evolutionarily unfamiliar physical landscapes; (2) excessive exposure to unnatural environmental light sources; (3) heightened exposure to urbanspecific threatening stimuli-especially in the context of specific genetic predispositions; and (4) population-based models incorporating a compilation of urban parameters such as increased population density, restricted resources and altered social/family structures. As discussed in this review, experimental approaches ranging from controlled laboratory investigations using rodent 
models to human field research in urban settings are necessary to understand the complex mechanisms underlying the emergence of urban-based psychiatric illness. Epidemiological research utilizing computer-generated models (e.g., agent-based models) also offer promise for understanding the relevance of urban-specific variables. Together, these actual and simulated data all point to the conclusion that the places we live leave a neural footprint that may have a significant impact on neural health and adaptive functions throughout an individual's lifetime and beyond. 


\section{References:}

Ahern, J., Cerda, M., Lippman, S.A., Tardiff, K.J., Vlahov, D., Galea, S., 2013. Navigating nonpositivity in neighbourhood studies: an analysis of collective efficacy and violence. J. Epidemiol. Community Health 67, 159-165.

Ahern, J., Galea, S., 2011. Collective efficacy and major depression in urban neighborhoods. Am. J. Epidemiol. 173, 1453-1462.

Alim T.N., Graves E., Mellman T.A., Aigbogun N., Gray E., Lawson W., Charney D.S., 2006. Trauma Exposure, Posttraumatic Stress Disorder and Depression in an African-American Primary Care Population. J. Natl. Med. Assoc. 98,1630-1636.

American Psychiatric Association, A.P., 2000. Diagnostic and Statistical Manual of Mental Disorders. $\left(4^{\text {th }}\right.$ ed, text review). Washington DC: Author

American Psychiatric Association., 2013. Diagnostic and Statistical Manual of Mental Disorders (5 $5^{\text {th }}$ ed.). Washington DC: Author.

Astell-Burt, T., Mitchell, R., Hartig, T., 2014. The association between green space and mental health varies across the lifecourse. A longitudinal study. J. Epidemiol. Community Health $68,578-583$.

Auchincloss, A.H., Roux, A.V.D., 2008. A new tool for epidemiology: the usefulness of dynamic-agent models in understanding place effects on health. Am. J. Epidemiol.168, 18. 
Bada, H. S., Das, A., Bauer, C. R., Shankaran, S., Lester, B., LaGasse, Hammond, J., Wright, L.L., Higgins, R., 2007. Impact of prenatal cocaine exposure on child behavior problems through school age. Pediatrics, 119(2), e348-359. doi: 10.1542/peds.2006-1404

Bada, H. S., Langer, J., Twomey, J., Bursi, C., Lagasse, L., Bauer, C. R., Shankaran, S., Lester, B.M., Higgins, R., Maza, P. L., 2008. Importance of Stability of Early Living Arrangements on Behavior Outcomes of Children With and Without Prenatal Drug Exposure. J. Dev. Behav. Pediatr., 29(3), 173-182.

Baldwin, J.M., 1896. A new factor in evolution. Am. Naturalist. 30, 441-451.

Bandura, A., 1977. Self-efficacy: Toward a unifying theory of behavioral change.

Psychol. Rev. 84, 191-215.

Banyard V.L., Williams L.M., Siegel J.A., 2003. The Impact of Complex Trauma and Depression on Parenting: An Exploration of Mediating Risk and Protective Factors. Child Maltreat. 8,334-349.

Bardi, M., Rhone, A.P., Franssen, C.L., Hampton, J.E., Shea, E.A., Hyer, M.M., Huber, J., Lambert, K.G., 2012. Behavioral training and predisposed coping strategies interact to influence resilience in male Long-Evans rats: implications for depression. Stress 15, 306-317.

Bardi, M., True, M., Franssen, C.L., Kaufman, C., Rzucidlo, A., Lambert, K.G., 2013. Effortbased reward (EBR) training enhances neurobiological efficiency in a problem-solving task: insights for depression therapies. Brain Research 1490, 101-110. 
Beard, J.R., Cerdá, M., Blaney, S., Ahern, J., Vlahov, D., Galea, S., 2009. Neighborhood characteristics and change in depressive symptoms among older residents of New York City. Am. J. Public Health 99, 1308.

Bedrosian, T.A., Fonken, L.K., Walton, J.C., Haim, A. Nelson, R.J., 2011. Dim light at Night provokes depression-like behaviors and reduces CA1 dendritic spine density in female hamsters. Psychoneuroendocrinology 36, 1062-1069.

Bedrosian, T.A., Weil, Z.M., Nelson, R.J., 2012. Citalopram improves depressive behaviors under light at night. Behavioral Neuroscience 126, 654-658.

Bedrosian T.A., Galan A., Vaughn C.A., Weil Z.M., Nelson R.J., 2013a. Nocturnal light alters diurnal patterns of cortisol and clock proteins in female hamsters. J. Neuroendocrinol. 25, 590-0606.

Bedrosian, T.A., Weil, Z.M., Nelson, R.J., 2013b. TNF $\alpha$ is implicated in a reversible depression-like phenotype provoked by chronic dim light at night. Mol. Psych., 18, 930936.

Bedrosian, T.A., Vaughn, C.A., Galan, A., Daye, Ghassan, Weil, Z.M., Nelson, R.J., 2013c. Night-time light exposure impairs mood in a wavelength-dependent manner. J. Neuroscience 33, 13801-13087

Bedrosian, T.A, Nelson, R.J., 2013. Influence of the modern light environment on mood. Mol. Psych., 18, 751-757.

Bennett, E.L., Diamond, M.C., Krech D., Rosenzweig, M.R., 1964. Chemical and anatomical plasticity of brain. Science 146, 610-618. 
Beyer, K.M.M., Kaltenbach, A., Szabo, A., Bogar, S., Nieto, F.J., Malecki, K.M., 2014.

Exposure to Neighborhood Green Space and Mental Health: Evidence from the Survey of the Health of Wisconsin. Int. J. Environ. Res. Public Health 11, 3453-3472.

Binder, E. B., Bradley, R. G., Liu, W., Epstein, M. P., Deveau, T. C., Mercer, K. B., Tang, Y., Gillespie, C.F., Heim, C.M., Nemeroff, C.B., Schwartz, A.C., Cubells, J.F., Ressler, K. J. (2008). Association of FKBP5 Polymorphisms and Childhood Abuse With Risk of Posttraumatic Stress Disorder Symptoms in Adults. JAMA 299(11), 1291-1305. doi: 10.1001/jama.299.11.1291

Blair, A., 2014. The longitudinal effects of neighborhood social and material deprivation change on psychological distress in urban, community-dwelling Canadian adults. The 20th IEA World Congress of Epidemiology (17-21 August 2014, Anchorage, AK).

Blask D.E., Brainard G.C., Dauchy R.T., Hanifin J.P., Davidson L.K., Krause J.A., Sauer L.A,, Rivera-Bermudez M.A., Dubocovich M.L., Jasser S.A., Lynch, D.T., Rollaq, M.D., Zalatan, F., 2005. Melatonin-depleted blood from premenopausal women exposed to light at night stimulates growth of human breast cancer xenografts in nude rats. Cancer Res. 65, 11174-11184.

Bonabeau, E., 2002. Agent-based modeling: Methods and techniques for simulating human systems. PNAS 99, 7280-7287.

Borniger J.C., Weil Z.M., Zhang N., Nelson R.J. 2013. Dim light at night does not disrupt timing or quality of sleep in mice. Chronobiol. Int., 30, 1016-1023.

Bremner J.D., Narayan M., Anderson E.R., Staib L.H., Miller H.L., Charney D.S., 2000. Hippocampal volume reduction in major depression. Am J Psychiatry, 157, 115-118. 
Breslau N., Kessler R.C., Chilcoat H.D., Schultz L.R., Davis G.C., Andreski P., 1998. Trauma and posttraumatic stress disorder in the community: the 1996 Detroit Area Survey of Trauma. Arch. Gen. Psychiat. 55, 626-632.

Breslau N., Wilcox H.C., Storr C.L., Lucia V.C., Anthony J.C., 2004. Trauma exposure and posttraumatic stress disorder: a study of youths in urban America. J. Urban Health 81, 530-544.

Breslau, J., Marshall, G.N., Pincus, H.A., Brown, R.A., 2014. Are mental disorders more common in urban than rural areas of the United States? J. Psychiat. Res.56, 50-55.

Cerda, M., Tracy, M., Ahern, J., Galea, S., 2014. Addressing population health and health inequalities: the role of fundamental causes. Am. J. Public Health 104 Suppl 4, S609-619.

Collishaw S., Dunn J., O'Connor T.G., Golding J., 2007. Maternal childhood abuse and offspring adjustment over time. Dev. Psychopathol. 19, 367-383.

Cooper P.J., Fearn V., Willetts L., Seabrook H., Parkinson M., 2006. Affective disorder in the parents of a clinic sample of children with anxiety disorders. J. Affect. Disorders 93, 205212.

Cutrona, C.E., Russell, D.W., Brown, P.A., Clark, L.A., Hessling, R.M., Gardner, K.A., 2005. Neighborhood context, personality, and stressful life events as predictors of depression among African American women. J. Abnorm. Psychol.114, 3.

Czeisler, C.A., Johnson, M.P., Duffy, J.F., Brown, E.N., Ronda, J.M., Kronauer, R.E., 1990. Exposure to bright light and darkness to treat physiologic maladaptation to night work. NEJM. 322, 1253-1259. 
Davis M., 1992. The role of the amygdala in fear-potentiated startle: implications for animal models of anxiety. Trends Pharmacol. Sci. 13, 35-41.

Davis M., Falls W.A., Campeau S., Kim M., 1993. Fear-potentiated startle: A neural and pharmacological analysis. Behav. Brain Res. 58. 175-198.

Darwin, C., 1868. The variation of Animals and Plants under Domestication (1s ed.). London: John Murray.

De Bellis M.D., Broussard E.R., Herring D.J., Wexler S., Moritz G., Benitez J.G., 2001. Psychiatric co-morbidity in caregivers and children involved in maltreatment: a pilot research study with policy implications. Child Abuse Negl. 25, 923-944.

Decatur, S., 2012. When the number 9 bus was like home, and downtown was my playground.

In: Piiparinen, R., Trubek, A., Rust Belt Chic. Cleveland OH: Rust Belt Chic Press.

de Vries, S., van Dillen, S.M.E., Groenewegen, P.P., Spreeuwenberg, P., 2013. Streetscape greenery and health: stress, social cohesion and physical activity as mediators. Soc. Sci. Med. 94, 26-33.

Dias B.G., Ressler K.J., 2014. Parental olfactory experience influences behavior and neural structure in subsequent generations. Nat. Neurosci. 17,89-96.

Diez Roux, A.V., Mair, C., 2010. Neighborhoods and health. Ann. N.Y. Acad. Sci. 1186, 125145.

Dulmus C.N., Wodarski J.S., 2000. Trauma-Related Symptomatology Among Children of Parents Victimized by Urban Community Violence. Am. J. Orthopsychiatry 70, 272-277.

Duman R.S., Monteggia L.M., 2006. A neurotrophic model for stress-related mood disorders. Biol. Psych. 59, 1116-1127. 
Echeverría, S., Diez-Roux, A.V., Shea, S., Borrell, L.N., Jackson, S., 2008. Associations of neighborhood problems and neighborhood social cohesion with mental health and health behaviors: the Multi-Ethnic Study of Atherosclerosis. Health Place 14, 853-865.

Egeland JA, Hostetter AM., 1983. Amish Study, I: Affective disorders among the Amish, 1976-1980. Am. J. Psych., 140, 56-61

Ekirch, R., 2006. At Day’s Close: Night in Times Past; W.W. Norton, New York.

Epstein, J.M., 1999. Agent-based computational models and generative social science. Generative Social Science: Studies in Agent-Based Computational Modeling 4, 4-46.

Epstein, J.M., Axtell, R.L., 1996. Growing artificial societies: Social science from the bottom up (complex adaptive systems). Boston: MIT Press.

Etkin A., Wager T., 2007. Functional Neuroimaging of Anxiety: A Meta-Analysis of Emotional Processing in PTSD, Social Anxiety Disorder, and Specific Phobia. Am. J. Psychiatry $164,1476-1488$.

Fawcett, N.R., Gullone, E., 2001. Cute and cuddly and a whole lot more? A call for empirical investigation into the therapeutic benefits of human-animal interaction for children. Behav. Change 18, 124-133.

Fonken L.K., Finy M.S., Walton J.C., Weil Z.M., Workman J.L., Ross J., Nelson R.J, 2009. Influence of light at night on murine anxiety- and depressive-like responses. Behav. Brain Res. 205, 349-354.

Fonken, L.K., Nelson, R.J., 2011. Illuminating the deleterious effects of light at night. F1000 Med. Reports, 3, 18 (doi:10.3410/M3-18). 
Freeman, H., Alpert, M., 1986. Prevalence of schizophrenia in an urban population. The British J. Psychiatry 149, 603-611.

Frewen P.A., Lanius R.A., 2006. Toward a psychobiology of posttraumatic self-dysregulation: reexperiencing, hyperarousal, dissociation, and emotional numbing. Ann. N.Y. Acad. Sci. 1071:110-124.

Frodl T., Meisenzahl E.M., Zetzsche T., Born C., Groll C., Jager M., Leinsinger, G., Bottlender, R., Hahn, K., Moller, H.J., 2002. Hippocampal changes in patients with a first episode of major depression. Am. J. Psychiatry, 159, 1112-1118.

Furr-Holden, C. D., Lee, M. H., Milam, A. J., Johnson, R. M., Lee, K. S., \& Ialongo, N. S., 2011. The growth of neighborhood disorder and marijuana use among urban adolescents: a case for policy and environmental interventions. J. Stud. Alcohol Drugs, 72(3), 371-379.

Galea, S., 2011. The urban brain: new directions in research exploring the relation between cities and mood-anxiety disorders. Depress. Anxiety 28, 857-862.

Galea, S., Ahern, J., Nandi, A., Tracy, M., Beard, J., Vlahov, D., 2007. Urban neighborhood poverty and the incidence of depression in a population-based cohort study. Ann. Epidemiol. 17, 171-179.

Galea, S., Ahern, J., Rudenstine, S., Wallace, Z., Vlahov, D., 2005. Urban built environment and depression: a multilevel analysis. Journal of Epidemiol. Community Health 59, 822-827.

Galea, S., Ahern, J., Vlahov, D., 2003. Contextual determinants of drug use risk behavior: a theoretic framework. J. Urban Health, 80 (4), 50-58. 
Galea, S., Hall, C., Kaplan, G.A., 2009. Social epidemiology and complex system dynamic modelling as applied to health behaviour and drug use research. Int. J. Drug Policy 20, 209-216.

Galea, S., Nandi, A., Vlahov, D., 2004. The social epidemiology of substance use. Epideoiol. Rev. 26, $36-52$.

Galea, S., Riddle, M., Kaplan, G.A., 2010. Causal thinking and complex system approaches in epidemiology. Int. J. Epidemiol. 39, 97-106.

Galea, S., Rudenstine, S., Vlahov, D., 2005. Drug use, misuse, and the urban environment. Drug Alcohol Rev. 24, 127-136.

Gapen, M., Cross, D., Ortigo, K., Graham, A., Johnson, E., Evces, M., Ressler, K.J., Bradley, B., 2011. Perceived neighborhood disorder, community cohesion, and PTSD symptoms among low-income African Americans in an urban health setting. Am. J. Orthopsychiatry 81, 31-37.

Gary, T.L., Stark, S.A., LaVeist, T.A., 2007. Neighborhood characteristics and mental health among African Americans and whites living in a racially integrated urban community. Health Place 13, 569-575.

Gillespie C.F., Bradley R.G., Mercer K., Smith A.K., Conneely K., Gapen M., Weiss T., Schwartz A.C., Cubells J.F., Ressler K.J., 2009. Trauma Exposure and Stress-Related Disorders in Inner City Primary Care Patients. Gen. Hosp. Psychiatry 31, 505-514.

Grant, B.F., Stinson, F.S., Dawson, D.A., Chou, S.P., Dufour, M.C., Compton, W., Pickering, R.P., Kaplan, K., 2004. Prevalence and Co-occurrence of Substance Use Disorders and IndependentMood and Anxiety Disorders: Results From the National Epidemiologic Survey on Alcohol and RelatedConditions. Arch. Gen. Psychiat. 61, 807-816. 
Grillon C., Dierker L., Merikangas K.R., 1997. Startle modulation in children at risk for an.xiety disorders and/or alcoholism. J. Am. Acad. Child Adolesc. Psychiatry 36, 925-932.

Grillon, C., Morgan, C. A., 1999. Fear-potentiated startle conditioning to explicit and contextual cues in Gulf War veterans with posttraumatic stress disorder. J. Abnor. Psychol. 108, $134-142$.

Hajszan T., Dow A., Warner-Schmidt J.L., Szigeti-Buck K., Sallam N.L., Parducz A., Leranth C., Duman R.S., 2009. Remodeling of hippocampal spine synapses in the rat learned helplessness model of depression. Biol. Psych., 65: 392-400.

Hajszan T, MacLusky NJ, Leranth C., 2005. Short-term treatment with the antidepressant fluoxetine triggers pyramidal dendritic spine synapse formation in rat hippocampus. Eur. J. Neurosci. 21, 1299-1303.

Hajszan T., Szigeti-Buck K., Sallam N.L., Bober J., Parducz A., Maclusky N.J., Leranth C., Duman, R.S., 2010. Effects of estradiol on learned helplessness and associated remodeling of hippocampal spine synapses in female rats. Biol. Psychiatry, 67, 168-174.

Hattar S., Kumar M., Park A., Tong P., Tung J, Yau K.W., Berson, D.M., 2006. Central projections of melanopsin-expressing retinal ganglion cells in the mouse. J. Comp. Neurol. 497, 326-349.

Healy D., Minors D.S., Waterhouse J.M., 1993. Shiftwork, helplessness and depression. J. Affect. Disord. 29, 17-25.

Hebb, D.O., 1949. The Organization of Behavior: A Neuropsychology Theory. New York: John Wiley and Sons.

Hidaka, B.H., 2012. Depression as a disease of modernity: explanations for increasing 
prevalence. J. Affective Disorders 140, 205-214.

Ickes, B.R., Pham, T.M., Sanders, L.A., Albeck, D.S., Mohammed, A.H., Granholm, A.C., 2000. Long-term environmental enrichment leads to regional increases in neurotropin levels in rat brain. Exp. Neurol. 164, 45-52.

Igarashi, M., Song, C., Ikei, H., Miyazaki, Y., 2014. Effect of stimulation by foliage plant display images on prefrontal cortex activity: a comparison with stimulation using actual foliage plants. J. Neuroimaging. DOI: 10.1111/jon.12078

Joens-Matre, R.R., Welk, G.J., Calabro, M.A., Russell, D.W., Nicklay, E., Hensley, L.D., 2008. Rural-urban differences in physical activity, physical fitness, and overweight prevalence of children. J. Rural Health 24, 49-54.

Johns, L.E., Aiello, A.E., Cheng, C., Galea, S., Koenen, K.C., Uddin, M., 2012. Neighborhood social cohesion and posttraumatic stress disorder in a community-based sample: findings from the Detroit Neighborhood Health Study. Social psychiatry psychiatr. Epidemiol. 47, 1899-1906.

Jovanovic, T., Norrholm, S. D., Blanding, N. Q., Davis, M., Duncan, E., Bradley, B., Ressler, K. J., 2010. Impaired fear inhibition is a biomarker of PTSD but not depression. Depress Anxiety, 27(3), 244-251.

Jovanovic T., Norrholm S.D., 2011. Neural mechanisms of impaired fear inhibition in posttraumatic stress disorder. Front. Behav. Neurosci. 5, 44.

Jovanovic T., Norrholm S.D., Davis J., Mercer K.B., Almli L., Nelson A., Cross D, Smith A., Ressler K.J,, Bradley B., 2012. PAC1 receptor (ADCYAP1R1) genotype is associated with dark-enhanced startle in children. Mol. Psychiatry 18, 742-743. 
Jovanovic T., Nylocks K.M., Gamwell K.L., Smith A., Davis T.A., Norrholm S.D., Bradley B., 2014. Development of fear acquisition and extinction in children: Effects of age and anxiety. Neurobiol. Learn Mem. 113,135-142.

Jovanovic T., Smith A., Kamkwalala A., Poole J.M., Samples T., Norrholm S.D., Ressler K.J., Bradley B., 2011. Physiological markers of anxiety are increased in children of abused mothers. J. Child Psychol. Psychiatry 52, 844-852.

Kamkwalala A., Norrholm S.D., Poole J.M., Brown A., Donely S., Duncan E., Bradley B., Ressler K.J., Jovanovic T., 2012. Dark-Enhanced Startle Responses and Heart-Rate Variability in a Traumatized Civilian Sample: Putative Sex-Specific Correlates of PTSD. Psychosom. Med. 74, 153-159.

Kaufman, J.S., Kaufman, S., Poole, C., 2003. Causal inference from randomized trials in social epidemiology. Soc. Sci. Med. 57, 2397-2409.

Kessler, R.C., McGonagle, K.A., Zhao, S., Nelson, C.B., Hughes, M., Eshleman, S., Wittchen, H.-U., Kendler, K.S., 1994. Lifetime and 12-month prevalence of DSM-III-R psychiatric disorders in the United States: results from the National Comorbidity Survey. Arch. Gen. Psychiatry 51, 8-9.

Kessler, R.C., Sonnega, A., Bromet, E., Hughes, M., Nelson, C.B., 1995. Posttraumatic stress disorder in the National Comorbidity Survey. Arch. Gen. Psychiatry 52, 1048-1060.

Klengel T., Mehta D., Anacker C., Rex-Haffner M., Pruessner J.C., Pariante C.M., Pace T.W.W., Mercer K.B., Mayberg H.S., Bradley B., Nemeroff C.B., Holsboer F., Heim C.M., Ressler K.J., Rein T., Binder E.B., 2013. Allele-specific FKBP5 DNA demethylation mediates gene-childhood trauma interactions. Nat. Neurosci. 16, 33-41.

Kloog I., Haim A., Stevens R.G., Barachana M., Portnov B.A., 2008. Light at night co- 
distributes with incident breast but not lung cancer in the female population of Israel. Chronobiol. Int. 25, 65-81.

Krabbendam, L., van Os, J., 2005. Schizophrenia and urbanicity: a major environmental influence-conditional on genetic risk. Schizophrenia Bull. 31, 795-799.

Kubzansky, L.D., Subramanian, S.V., Kawachi, I., Fay, M.E., Soobader, M.-J., Berkman, L.F., 2005. Neighborhood contextual influences on depressive symptoms in the elderly. Am. J. Epidemiol. 162, 253-260.

Laland, K.N., Brown, G.R., 2006. Niche construction, human behavior, and the adaptive-lag hypothesis. Evol.. Anthropology. 15, 95-104.

Last C.G., Hersen M., Kazdin A., Orvaschel H., Perrin S., 1991. Anxiety disorders in children and their families. Arch. Gen. Psychiatry 48, 928-934.

Latkin, C.A., Curry, A.D., 2003. Stressful neighborhoods and depression: a prospective study of the impact of neighborhood disorder. J. Health Soc. Behav. 44, 34-44.

Leventhal, T., Brooks-Gunn, J., 2003. Moving to opportunity: an experimental study of neighborhood effects on mental health. Am. J. Public Health 93, 1576-1582.

Liberzon I., Martis B., 2006. Neuroimaging Studies of Emotional Responses in PTSD. Ann. NY Acad. Sci. 1071, 87-109.

Liberzon I., Taylor S.F., Amdur R., Jung T.D., Chamberlain K.R., Minoshima S., Koeppe R.A., Fig L.M., 1999. Brain activation in PTSD in response to trauma-related stimuli. Biol. Psychiatry 45, 817-826.

Luthar S.S., Sexton C.C., 2007. Maternal drug abuse versus maternal depression: Vulnerability and resilience among school-age and adolescent offspring. Dev. Pschopathol. 19, 205225. 
Laland, K.N., Brown, G.R., 2006. Niche construction, human behavior, and the adaptive-lag hypothesis. Evol. Anthropol.15, 95-104.

Lambert, K.G., 2006. Rising rates of depression in today's society: consideration for the roles of effort-based rewards and enhanced resilience in day-to-day functioning. Neurosci. Biobehav. Rev. 30, 319-324.

Lambert, K. G., Hyer, M., Rzucidlo, A., Scott, S., Terhune-Cotter, B., Hazelgrove, A., Silva, I., Kinsley, C.H., Bardi, M., 2014a. Natural-enriched habitats enhance environmental engagement and emotional resilience in rats. Unpublished manuscript

Lambert, K.G., Hyer, M.M., Rzucidlo, A.A., Bergeron, T., Landis, T., Bardi, M., 2014 b. Contingency-based emotional resilience: Effort-based reward training and flexible coping lead to adaptive responses to uncertainty in male rats. Front. Behav. Neurosci. Doi:10.3389/fnbeh.2014.00124.

Larson, N., Ward, D.S., Neelon, S.B., Story, M. 2011. What role can child-care settings play in obesity prevention? A review of the evidence and call for research efforts. J. Am. Dietetic Ass. 111, 1343-1362.

Lear, L., 2007. Beatrix Potter: A Life in Nature. New York: St. Martin's Griffin.

Lederbogen, F., Kirsch, P., Haddad, L., Streit, F., Tost, H., schuch, P., Wust, S., Pruessner, J.C., Rietschel, M., Deuschle, M., Meyer-Linderberg, A., 2011. City living and urban upbringing affect neural social stress processing in humans. Nature 474, 498501.

LeGates TA, Altimus CM, Wang H, Lee HK, Yang S, Zhao H et al. 2012. Aberrant light directly impairs mood and learning through melanopsin-expressing neurons. Nature, 491: 594598. 
Lowe, S.R., Galea, S., Uddin, M., Koenen, K.C., 2014. Trajectories of Posttraumatic Stress Among Urban Residents. Am. J. Community Psychol. 53, 159-172.

Loucaides, C.A., Chedzoy, S.M., Bennett, N., 2004. Differences in physical activity levels between urban and rural school children in Cyprus. Health Educ. Res. 19, 138147.

Maciejewski, P.K., Prigerson, H.G., Mazure, C.M., 2000. Self-efficacy as a mediator between stressful life events and depressive symptoms: Differences based on history of prior depression. Br. J. Psychiatry 176, 373-378.

Mair, C., Diez Roux, A.V., Morenoff, J.D., 2010. Neighborhood stressors and social support as predictors of depressive symptoms in the Chicago Community Adult Health Study. Health Place 16, 811-819.

Mair, C.F., Roux, A.V.D., Galea, S., 2008. Are neighborhood characteristics associated with depressive symptoms? A critical review. J. Epidemiol. Comm. Health, 62, 940-946.

Maller, C., Townsend, M., Pryor, A., Brown, P., St. Leger, L., 2005. Healthy nature healthy people: 'contact with nature' as an upstream health promotion intervention for populations. Health Promot. Int. 21, 45-54.

Maniadakis, M., Trahanias, P., 2006. Modelling brain emergent behaviours through coevolution of neural agents. Neural Net. 19, 705-720.

McAuley, E., White, S.M., Rogers, L.Q., Motl, R.W., Courneya, K.S., 2010. Physical activity and fatigue in breast cancer and multiple sclerosis: Psychosocial mechanisms. Psychosom. Med. 72, 88-96.

McClung C.A., 2007. Circadian genes, rhythms and the biology of mood disorders. Pharmacol. Ther. 11, 222-232. 
McClung CA., 2011. Circadian rhythms and mood regulation: insights from pre-clinical models. Eur. Neuropsychopharmacol., 21(Suppl 4), S683-S693.

McClure E.B., Brennan P.A., Hammen C., Le Brocque R.M., 2001. Parental anxiety disorders, child anxiety disorders, and the perceived parent-child relationship in an Australian highrisk sample. J. Abnorm. Child. Psychol. 29, 1-10.

Merikangas K.R., Avenevoli S., Dierker L., Grillon C., 1999. Vulnerability factors among children at risk for anxiety disorders. Biol. Psychiatry 46, 1523-1535.

Miles, R., Coutts, C., Mohamadi, A., 2012. Neighborhood urban form, social environment, and depression. J. Urban Health 89, 1-18.

Mineka, S., Ohman, A., 2002. Phobias and preparedness: The selective, automatic, and encapsulated nature of fear. Biol. Psychiatry 52, 927-937.

Mineka, S., Zinbarg, R., 2006. A contemporary learning theory perspective on the etiology of anxiety disorders. Am. Psychol. 61, 10-26.

Mitra, R., Sapolsky, R.M., 2012. Short-term enrichment makes male rats more attractive, more defensive and alters hypothalamic neurons. PLoS ONE 7, e36092.

Morenoff, J.D., Sampson, R.J., Raudenbush, S.W., 2001. Neighborhood inequality, collective efficacy, and the spatial dynamics of urban violence. Criminology 39, 517-559; pg. 521.

Narasimamurthy, R., Hatori, M., Nayak, S.K., Liu, F., Panda, S., Verma, I.M., 2012. Circadian clock protein cryptochrome regulates the expression of proinflammatory cytokines.

PNAS 109, 12662-12667.

Navara K.J., Nelson R.J., 2007. The dark side of light at night: physiological, epidemiological, and ecological consequences. J. Pineal Res. 43, 215-224. 
Nemeroff C.B., Bremner J.D., Foa E.B., Mayberg H.S., North C.S., Stein M.B., 2006.

Posttraumatic stress disorder: a state-of-the-science review. J. Psychiat. Res.40, 1-21.

Nestler E.J., Barrot M., DiLeone R.J., Eisch A.J, Gold SJ, Monteggia LM., 2002. Neurobiology of depression. Neuron, 34: 13-25.

Nithianantharajah, J., Hannan, A.J., 2006. Enriched environments, experience-dependent plasticity and disorders of the nervous system. Nature Rev. Neurosci. 7, 697-709.

Norrholm, S. D., Jovanovic, T., Olin, I. W., Sands, L. A., Karapanou, I., Bradley, B., \& Ressler, K. J. (2011). Fear extinction in traumatized civilians with posttraumatic stress disorder: relation to symptom severity. Biol Psychiatry, 69(6), 556-563. doi: S00063223(10)00949-2 [pii]

Oakes, J.M., 2004. The (mis) estimation of neighborhood effects: causal inference for a practicable social epidemiology. Soc. Sci. Med. 58, 1929-1952.

Oakes, J.M., Kaufman, J.S., 2006. Methods in social epidemiology. John Wiley \& Sons.

Pearl, J., 2000. The logic of counterfactuals in causal inference (Discussion of 'Causal inference without counterfactuals'), J. Am. Statist. Assoc. 95, 428-435.

Pearl, J., 2009. Causal influence in statistics: An Overview. Statistics Surveys, 3, 96-146.

Peen, J., Schoevers, R.A., Beekman, A.T., Dekker, J., 2009. The current status of urban-rural differences in psychiatric disorders. Acta Psychiatrica Scandinavica 121, 84-93.

Peen, J., Schoevers, R.A., Beekman, A.T., Dekker, J., 2010. The current status of urban-rural differences in psychiatric disorders. Acta Psychiatrica Scandinavica 121, 84-93.

Pena, Y., Prunell, M., Rotllant, D., Armario, A., Escorihuela, R.M., 2009. Enduring effects of environmental enrichment from weaning to adulthood on pituitary-adrenal function, prepulse inhibition and learning in male and female rats. Psychoneuroendocrinology 
34,1390-1404.

Petros, N., Opacka-Juffry, J., Huber, J.H., 2013. Psychometric and neurobiological assessment of resilience in a non-clinical sample of adults. Psychoneuroendocrinology 38, 2099-2108.

Rauch S.L., Shin L.M., Phelps E.A., 2006. Neurocircuitry Models of Posttraumatic Stress Disorder and Extinction: Human Neuroimaging Research-Past, Present, and Future. Biol. Psychiatry 60, 376-382.

Rauch S.L., Whalen P.J., Shin L.M., McInerney S.C., Macklin M. L, Lasko N. B., Orr S.P., Pitman R. K. 2000. Exaggerated amygdala response to masked facial stimuli in posttraumatic stress disorder: a functional MRI study. Biol. Psychiatry 47,769-776.

Reeb-Sutherland BC, Helfinstein SM, Degnan KA, PÃ\%oRez-Edgar K, Henderson HA, Lissek S, Chronis-Tuscano A, Grillon C, Pine DS, Fox NA (2009) Startle Response in Behaviorally Inhibited Adolescents With a Lifetime Occurrence of Anxiety Disorders. J. Am. Acad Child Adoles. Psychiatry 48, 610-617.

Ressler KJ, Mercer KB, Bradley B, Jovanovic T, Mahan A, Kerley K, Norrholm SD, Kilaru V, Smith AK, Myers AJ, Ramirez M, Engel A, Hammack SE, Toufexis D, Braas KM, Binder EB, May V (2011) Post-traumatic stress disorder is associated with PACAP and the PAC1 receptor. Nature 470:492-497.

Richardson, E.A., Pearce, J., Mitchell, R., Kingham, S., 2013. Role of physical activity in the relationship between urban green space and health. Public.Health 127, 318-324.

Riolo, S. A., Nguyen, T. A., Greden, J. F., King, C. A. 2005. Prevalence of depression by race/ethnicity: findings from the National Health and Nutrition Examination Survey III. Amer. J. Public Health, 95, 998-1000. 
Roe, J.J., Thompson, C.W., Aspinall, P.A., Brewer, M.J., Duff, E.I., Miller, D., Mitchell, R., Clow, A., 2013. Green space and stress: evidence from cortisol measures in deprived urban communities. Int. J. Environ. Res. Public Health 10, 4086-4103.

Rosenzweig, M.R., Bennett, E.L., 1996. Psychobiology of plasticity: effects of training and experience on brain and behavior. Behav. Brain Res. 78, 57-65.

Rosenzweig, M.H., Bennett, E.I., Diamond, M.C., 1972. Brain changes in response to experience. Scientific American February, 22-30.

Ross, C.E., Mirowsky, J., 2001. Neighborhood disadvantage, disorder, and health. J. Health Soc Behav. 42, 258-276.

Sanghavi M., Mintun M.A., Gado MH. 1999. Depression duration but not age predicts hippocampal volume loss in medically healthy women with recurrent major depression. J. Neurosci. 19, 5034-5043.

Saarloos, D., Alfonso, H., Giles-Corti, B., Middleton, N., Almeida, O.P., 2011. The built environment and depression in later life: The health in men study. Am. J. Geriatric Psychiatry 19, 461-470.

Sack W.H., Clarke G.N., Seeley J., 1995. Posttraumatic Stress Disorder across Two Generations of Cambodian Refugees. J. Am. Acad. Child Adol. Psychiatry 34,1160-1166.

Sampson, R.J., Raudenbush, S.W., Earls, F., 1997. Neighborhoods and violent crime: A multilevel study of collective efficacy. Science 277, 918-924.

Sampson, R.J., Wikstrom, P.O., 2007. The Social Order of Violence in Chicago and Stockholm Neighborhoods: A Comparative Inquiry. In: Shapiro, I., Kalyvas, S., Masoud, T. (Eds.), Order, Conflict, and Violence. Cambridge University Press, New York and Cambridge.

Schewenius, M., McPhearson, T., Elmqvist, T., 2014. Opportunities for increasing resilience 
and sustainability of urban social-ecological systems: Insights from the URBES and the cities and biodiversity outlook projects. AMBIO 43, 434-444.

Schilling E.A., Aseltine R.H.J., Gore S., 2007. Adverse childhood experiences and mental health in young adults: a longitudinal survey. BMC Public Health 7, 1-10.

Schwartz A.C., Bradley R.L., Sexton M., Sherry A., Ressler K.J., 2005. Posttraumatic Stress Disorder Among African Americans in an Inner City Mental Health Clinic. Psychiatr. Serv. 56, 212-215.

Scott A.J., Monk T.H., Brink L.L., 1997. Shiftwork as a risk factor for depression: a pilot study. Int. J. Occup. Environ Health 3, S2-S9.

Seligman, M.E.P., Maier, S.F., 1967. Failure to escape traumatic shock. J. Exp. Psychology 74, 109; doi: 10.1037/h00024514.

Seto, K.C., Guneralp, B., Hutyra, L.R., 2012. Global forecasts of urban expansion to 2030 and direct impacts on biodiversity and carbon pools. PNAS. 109, 16083-16088.

Shafer, G., 1995. Philosophical foundations for causal networks, Advances in Intelligent Computing-IPMU'94. Springer, pp. 1-12.

Sheline Y.I., Sanghavi M., Mintun M.A., Gado M.H., 1999. Depression duration but not age predicts hippocampal volume loss in medically healthy women with recurrent major depression. J. Neurosci. 19, 5034-5043.

Shin L.M., Orr S.P., Carson M.A., Rauch S.L., Macklin M.L., Lasko N.B., Peters P.M., Metzger L.J., Dougherty D.D., Cannistraro P.A., Alpert N.M., Fischman A.J., Pitman R.K., 2004. Regional Cerebral Blood Flow in the Amygdala and Medial Prefrontal Cortex During Traumatic Imagery in Male and Female Vietnam Veterans With PTSD. Arch. Gen. Psychiatry 61, 68-176. 
Shin L.M., Rauch S.L., Pitman R. K., 2006. Amygdala, Medial Prefrontal Cortex, and Hippocampal Function in PTSD. Ann. N.Y. Acad. Sci. 1071, 67-79.

Silver, E., Mulvey, E.P., Swanson, J.W., 2002. Neighborhood structural characteristics and mental disorder: Faris and Dunham revisited. Soc. Sci. Med. 55, 1457-1470.

Simons, R.L., Simons, L.G., Burt, C.H., Brody, G.H., Cutrona, C., 2005. Collective efficacy, authoritative parenting and delinquency: A longitudinal test of a model integrating community- and family-level processes. Criminology 43, 989-1029.

Simpson, J., Kelly, J.P., 2012. The effects of isolated and enriched housing conditions on baseline and drug-induced behavioural responses in the male rat. Behav. Brain Res. 234, 175-183.

Sorscher N., Cohen L.J., 1997. Trauma in children of Holocaust survivors: Transgenerational effects. Am. J. Orthopsychiatry 67, 493-500.

Stafford, M., McMunn, A., Zaninotto, P., Nazroo, J., 2011. Positive and negative exchanges in social relationships as predictors of depression: evidence from the English Longitudinal Study of Aging. J. Aging Health 0898264310392992.

Stevens J.S., Almli L.M., Fani N., Gutman D.A., Bradley B., Norrholm S.D., Reiser E., Ely T.D., Dhanani R., Glover E.M., Jovanovic T, Ressler K.J., 2014. PACAP receptor gene polymorphism impacts fear responses in the amygdala and hippocampus. Proc. Natl. Acad. Sci. 111, 3158-3163.

Stevens R.G., Brainard G.C., Blask D.E., Lockley S.W., Motta M.E., 2013a. Adverse health effects of nighttime lighting: comments on American Medical Association policy statement. Am. J. Prev. Med. 45, 343-346. 
Stevens J.S., Jovanovic T., Fani N., Ely T.D., Glover E.M., Bradley B., Ressler K.J., $2013 b$. Disrupted amygdala-prefrontal functional connectivity in civilian women with posttraumatic stress disorder. J. Psychiat. Res. 7, 1469-1478.

Starka, L., Duskova, M., Hill, M., 2014. Dehydroepiandrosterone: a neuroactive steroid. J. Steroid Biochem Molecul. Biol. http://dx.doi.org/10.1016/j.jsbmb.2014.03.008.

Sternberg, E.M., 2009. Healing spaces: The science of place and well-being. Cambridge, MA: Harvard University Press.

Switzer G.E., Dew M.A., Thompson K., Goycoolea J.M., Derricott T., Mullins S.D., 1999 Posttraumatic Stress Disorder and Service Utilization Among Urban Mental Health Center Clients. J. Traumatic Stress 12, 25-39.

Tandon, P.S., Zhou, C., Christakis, D.A., 2012. Frequency of parent-supervised outdoor play of US preschool-aged children. Archives of Pediatric and Adolescent Medicine 166, 707712.

Then, F.S., Luppam M., Schroeter, M.L., Konig, H.H., Angermeyer, M.C., Riedel-Heller, S.G., 2013. Enriched environment at work and the incidence of dementia: Results of the Leipzig Longitudinal Study of the aged. PLOS ONE 8, e70906.

Ulrich, R.S., Simons, R.F., Losito, B.D., Fiorito, E., Miles, M.A., Zelson, M. Stress recovery during exposure to natural and urban environments. J Environ Psychol. 11, 201-230.

United Nations Department of Economic and Social Affairs (UNDESA). 2011. Population distribution, urbanization, internal migration and development: An international perspective. New York: United Nations.

Ursano, R.J., McKibben, J.B.A., Reissman, D.B., Liu, X., Wang, L., Sampson, R.J., Fullerton, C.S., 2014. Posttraumatic Stress Disorder and Community Collective Efficacy following the 2004 Florida Hurricanes. PloS ONE 9, e88467. 
US Department of Justice, 2011. Homicide Trends in the United States, 1980-2008. Bureau of Justic Statistics, Washington, DC.

Van Praag, H., Kempermann, G., Gage, F.H., 2000. Neural consequences of environmental enrichment. Nature Rev. Neurosci. 1, 191-198.

Varki, A., Geschwind, D.H., Eichler, E.E., 2008. Explaining human uniqueness: Genome interactions with environment, behavior and culture. Nature Rev. Genetics 9, 749763.

Wade R., Shea J.A., Rubin D., Wood J., 2014. Adverse Childhood Experiences of Low-Income Urban Youth. Pediatrics 134:e13-e20.

Westman J.A., Ferketich A.K., Kauffman R.M., MacEachern S.N., Wilkins 3rd JR, Wilcox P.P. et al., 2010. Low cancer incidence rates in Ohio Amish. Cancer Causes Contr. $21,69-75$.

Wight, R.G., Ko, M.J., Aneshensel, C.S., 2010. Urban neighborhoods and depressive symptoms in late middle age. Res. Aging, 33, 28-50.

Wilkinson, A., 2007. No obstacles: Navigating the world by leaps and bounds. The New Yorker Magazine, http://www.newyorker.com/magazine/2007/04/16/no-obstacles (accessed 9/24/2014).

Wilson, E.O., 1984. Biophilia. Cambridge, MA: Harvard University Press.

Wilson, E.O., 1993. Biophilia and the conservation ethic. In S.R. Kellert, E.O. Wilson (Eds.), The Biophilia Hypothesis (pp-31-41). Washington DC: Island Press.

Wolch, J.R., Byrne, J., Newell, J.P., 2014. Urban green space, public health, and environmental justice: The challenge of making cities 'just green enough.' Landscape Urban Planning. 125, 234-244. 
World Health, O., 2012. Global Health Observatory:(GHO). World Health Organization.

Yehuda R., Bierer L.M., 2008. Transgenerational transmission of cortisol and PTSD risk. Prog. Brain. Res. 167, 121-135.

Yehuda, R., Blair, W., Labinsky, E., \& Bierer, L. M. (2007). Effects of parental PTSD on the cortisol response to dexamethasone administration in their adult offspring. Am. J. Psychiatry, 164(1), 163-166.

Yehuda R, Halligan S.L., Bierer L.M., 2001. Relationship of parental trauma exposure and PTSD to PTSD, depressive and anxiety disorders in offspring. J. Psychiatr. Res. 35:261270.

Yehuda, R., Schmeidler, J., Siever, L. J., Binder-Brynes, K., \& Elkin, A., 1997. Individual differences in posttraumatic stress disorder symptom profiles in Holocaust survivors in concentration camps or in hiding. J. Trauma Stress, 10(3), 453-463.

Yehuda, R., Schmeidler, J., Giller, E. L., Jr., Siever, L. J., \& Binder-Brynes, K., 1998. Relationship Between Posttraumatic Stress Disorder Characteristics of Holocaust Survivors and Their Adult Offspring. Am. J. Psychiatry, 155(6), 841-843. 

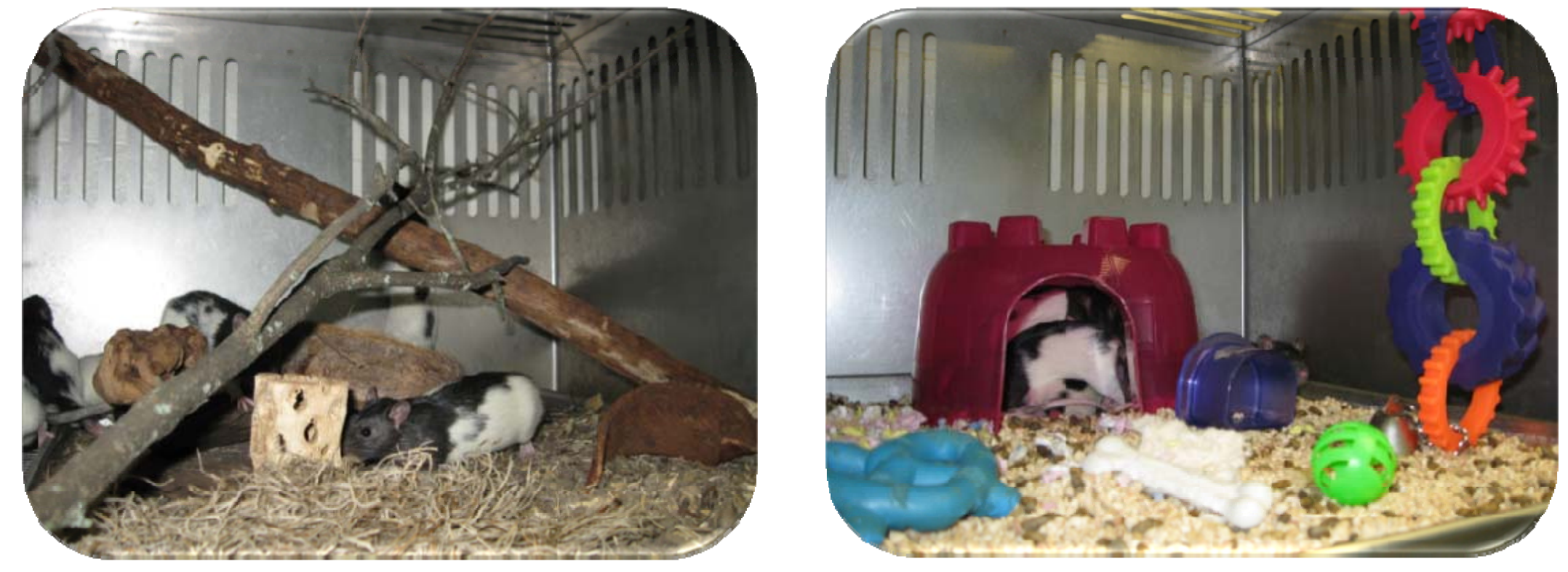

Figure 1. Examples of natural-enriched (left) and artificial-enriched (right) environments. Groups of 10 animals were housed in these environments in which an equal number of objects, with similar functions, were presented to the animals. 


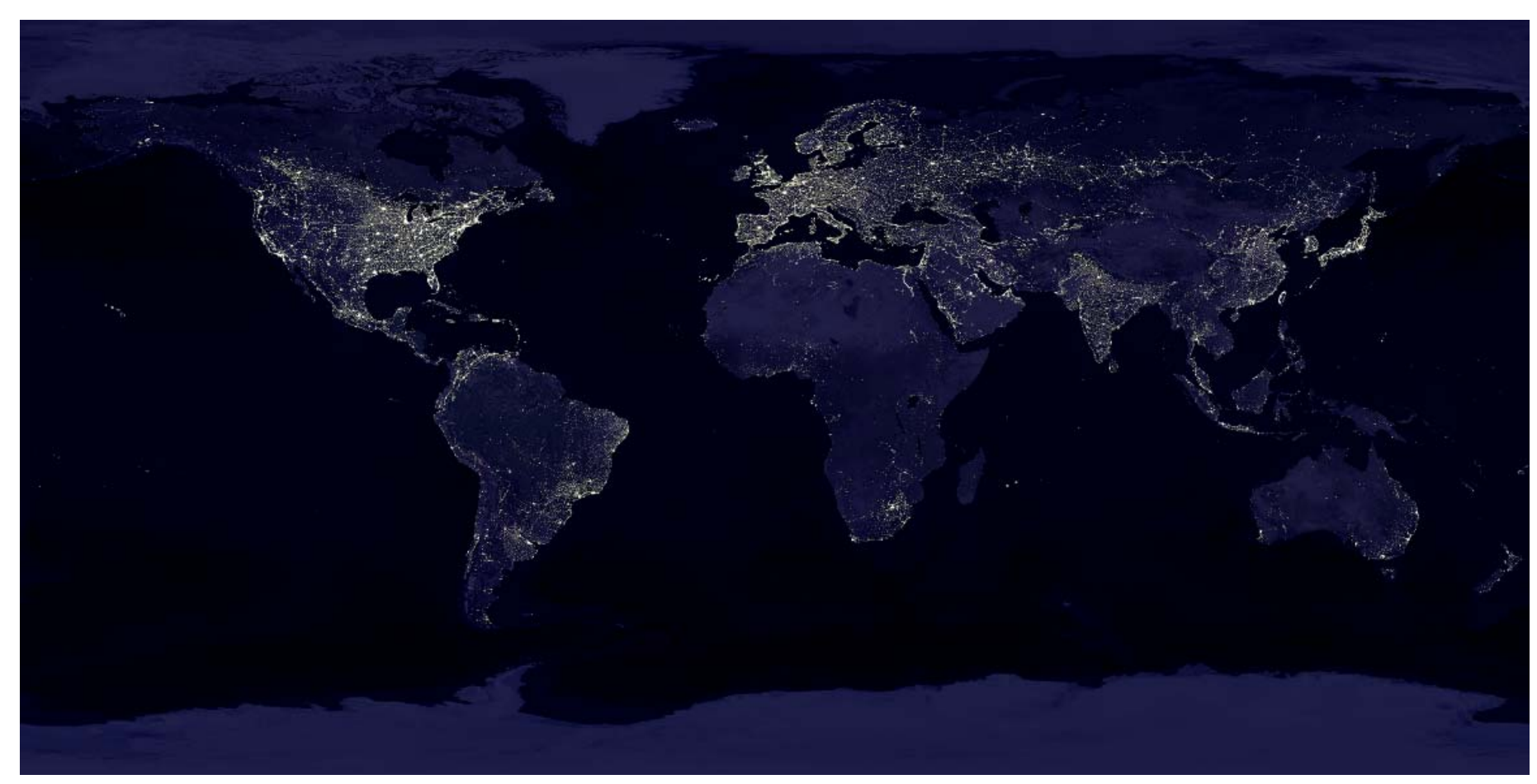

FIGURE 2. Artificial light at night as seen from space. Images are composites acquired by the NASA Suomi NPP satellite in 2012. A TIFF file is available at: earth lights 4800.tif 


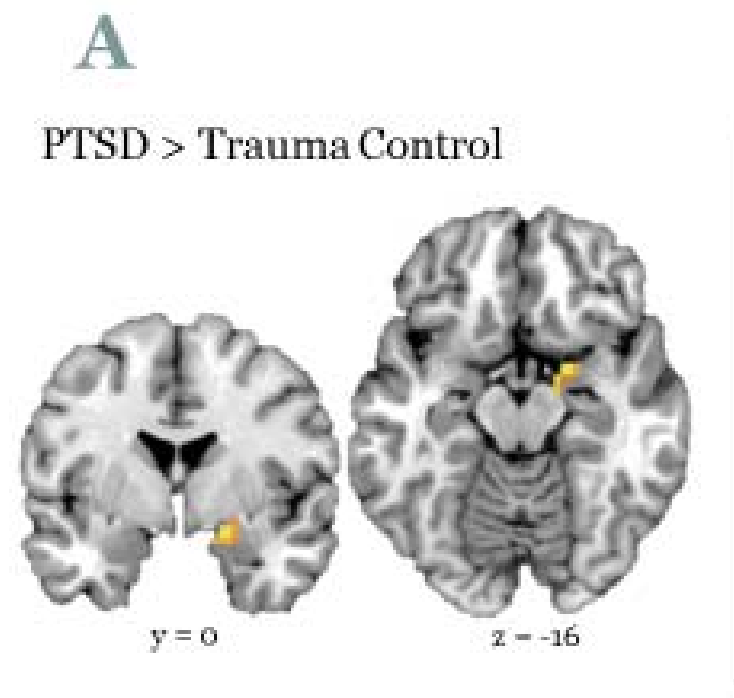

\section{B}

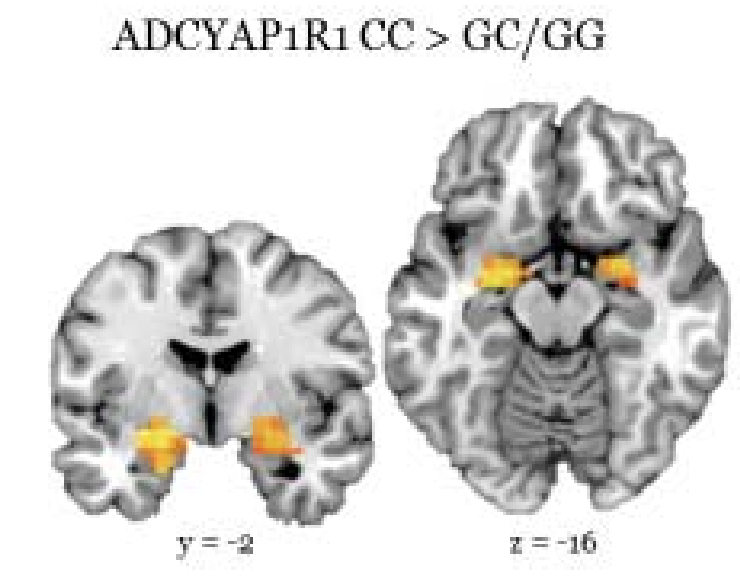

$t$-score

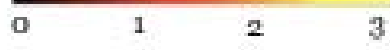

Figure 3. FIGURE 3. Brain activation to fearful vs. neutral faces is higher in A) Subjects with PTSD compared to trauma controls, and B) ACYAP1R1 CC genotype compared to $\mathrm{G}$ allele carriers. 


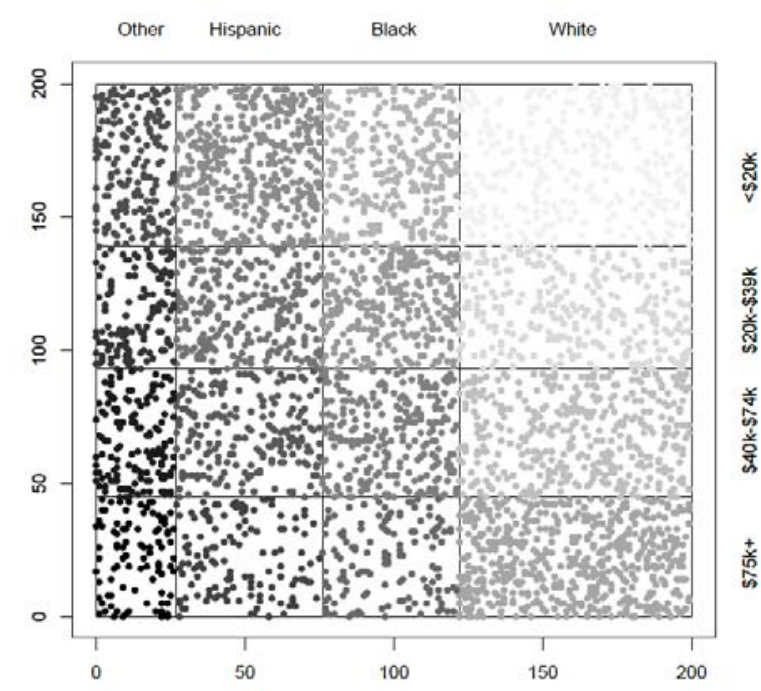

Figure 4. Agent locations in a grid of neighborhoods, with Agents (a) segregated in neighborhoods by race and Income, or (b) assigned random locations

Note. Each racial/ethnic group is represented by a different shade of gray (black: other non-Hispanic; medium gray: Hispanic; light gray: Black non-Hispanic; lightest gray: White non-Hispanic). Darker circles reflect higher income levels within each racial/ethnic group.

Figure taken from: (Cerda et al., 2014). Figure copyright: American Public Health Association. 